\title{
Basics of Dental Implantology for the Oral Surgeon
}

\author{
Supriya Ebenezer, Vinay V. Kumar, and Andreas Thor
}

\subsection{History and Evolution of Dental Implants}

Modern implant dentistry started more than 50 years ago when Dr. P.I. Brånemark, a Professor from the University of Gothenburg (Sweden), discovered in rabbit studies that titanium chambers placed in the fibula became firmly anchored in bone and could not be removed. Later, this direct bone-toimplant contact was termed osseointegration [1]. He demonstrated that titanium was structurally integrated into living bone with a high degree of predictability and without longterm soft-tissue inflammation or fixture rejection. He introduced a two-stage threaded root form pure titanium implant that was placed in patients in 1965. Therefore, Prof. P.I. Brånemark is recognized as the most important pioneer in modern implant dentistry.

The second pioneer is Prof. Andre Schroeder from the University of Bern (Switzerland) experimented with prototype dental implants in the early 1970s and could demonstrate first osseointegration in nondecalcified histologic sections [1]. Both pioneers with their teams, independent of each other, performed several preclinical and clinical studies to establish the current scientific basis for dental implantology. This was the start to successful osseointegration in dentistry.

Between the 1970s and the 1980s, companies presented different implant designs such as the Tübingen implants made of aluminum oxide, the IMZ titanium plasma-sprayed

Electronic Supplementary Material The online version of this chapter (https://doi.org/10.1007/978-981-15-1346-6_18) contains supplementary material, which is available to authorized users.

S. Ebenezer $(\square)$

Department of Oral Surgery and Stomatology, University of Bern, Bern, Switzerland

V. V. Kumar · A. Thor

Department of Maxillofacial and Plastic Surgery, Uppsala

University Academic Hospital, Uppsala, Sweden surface, and the American Core vent implants made of titanium aluminum vanadium alloy [1]. However, based on the research from Albrektsson, commercially pure titanium became the material of choice. One-piece implants slowly evolved to two-piece implants to provide prosthetic flexibility.

Over the next 15 years, implantology shifted from the treatment of fully edentulous patients to the treatment of partially edentulous patients as well. Prosthetic components for the rehabilitation of different edentulous situations emerged, and different surgical techniques and regenerative materials were developed to improve the hard and soft tissues around implants. Concepts of implant placement, loading, occlusion, and maintenance evolved. Progress was made in implant surface technology, which permitted the use of shorter and narrower implants and reduced loading time [2]. Over the last decade, development has included strategies to provide long-term stability with optimum functional, esthetic, and phonetic results along with reduced complications. Advanced diagnostic aids, such as cone beam computed tomography (CBCT), enabled proper assessment of the surgical site and surgical planning to provide better outcomes. Devices to examine implant stability objectively, using resonance frequency analysis, improved the quality of treatment provided. Digital technology is increasingly being incorporated to improve accuracy, minimize invasiveness, and fulfill esthetic demands. On the material front, ceramic implants and implants using alloys of increased strength have been introduced [2]. The field of implantology is a fastevolving one where the clinician has to be constantly updated to keep pace.

\subsection{The Concept of Osseointegration}

Titanium implants could become permanently incorporated within bone, such that the two could not be separated without fracture [3]. Osseointegration was the term given to this con- 
tact and refers to a direct bone to metal interface without interposition of soft tissue seen at the optical microscope level. Osseointegration is defined as "a direct structural and functional connection between ordered living bone and the surface of a load-carrying implant." [4]

\subsubsection{The Biological Process of Osseointegration}

The cellular response after implantation depends on implant surface characteristics, the stability, and heating injuries of the host bone. Bone healing around implants involves a cascade of cellular and extracellular biological events (similar to fracture healing) until the entire implant surface is embedded in bone.

The first biological component to contact the implant surface is blood and blood cells from the surrounding vasculature. These blood cells are activated and release cytokines and other growth and differentiation factors on and around the implant. Platelets undergo biochemical and morphological changes due to contact with the implant surface and undergo adhesion, spreading, and aggregation. They induce phosphotyrosine, increase intracellular calcium, and cause hydrolysis of phospholipids to form a fibrin matrix that regulates cell adhesion and binding of minerals. This matrix is a calcified afibrillar layer consisting of osteoid and lamina limitans (organic layer) that is rich in calcium, phosphorus, osteopontin, and bone sialoprotein [5]. This matrix acts as a scaffold for osteogenic cells to migrate and differentiate to form osteoid and trabecular bone (osteoconduction), which will ultimately remodel to form lamellar bone around the implant surface. The ability of the implant surface to retain fibrin attachment during the initial phase is critical in determining if the migrating cells reach the fibrin clot. Roughened surfaces promote osteoconduction. The chemistry of the implant surface also influences osteoconduction, and for example, hydrophilic implant surfaces have increased osteoconduction as compared to hydrophobic surfaces.

Peri-implant osteogenesis occurs in two ways with the native bone as described by Osborn and Newesley in 1980 .

1. Distance osteogenesis is a phenomenon that occurs from the native bone toward the implant surface. The existing bone surface provides a population of osteogenic cells, which lay down matrix, slowly encroach on the fibrinmeshwork-covered implant surface, and connect to this network as osteogenesis progresses. Osteoclasts, derived from mononuclear cells from the surrounding marrow spaces, remodel the old bony surface before new bone is laid down [5].

2. Contact osteogenesis occurs from the surface of the implant toward the healing bone. The fibrin-covered

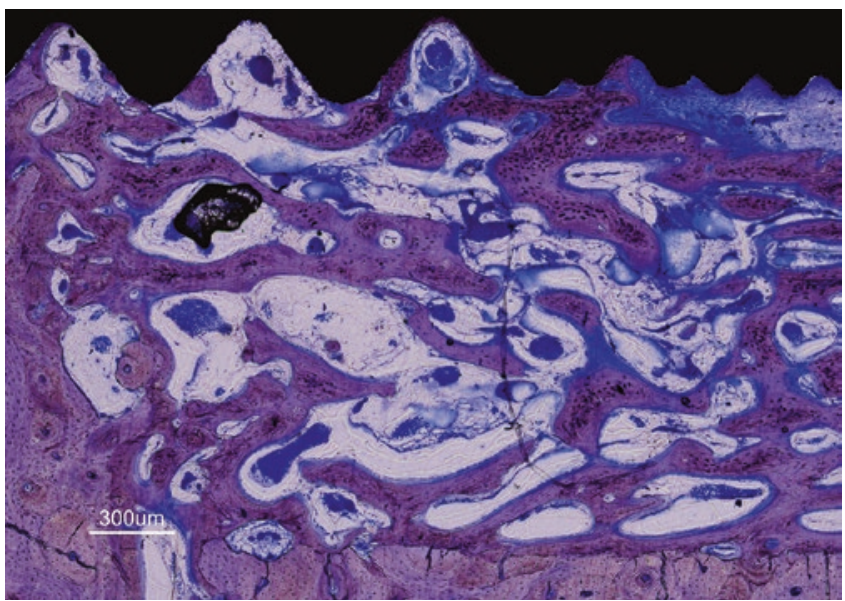

CAssociation of Oral and Maxillofacial Surgeons of India

Fig. 18.1 Histology of osseointegration. Osseointegration is defined as the direct apposition of bone onto the titanium implant surface as seen in this histology section

implant surface that has attracted osteogenic cells slowly has calcified afibrillar tissue forming into it. Blood vessels and mesenchymal cells fill up the spaces in between. Cement lines of poorly mineralized osteoid separate the areas of resorption and initiation. Woven and trabecular bone fill the initial gap and provide biological fixation to the implant at about 10-14 days postsurgery. However, the random orientation of the collagen fibers gives it reduced mechanical properties as compared to lamellar bone. This biological fixation differs from primary stability obtained at implant placement and is commonly seen with rough implant surfaces. Woven bone is slowly remodeled in response to stress and mechanical loading and replaced by lamellar bone until it reaches a high degree of mineralization. At approximately 3 months postimplant placement, the bone is a mixture of both woven and lamellar matrix [6].

(Figure 18.1: histology showing adequate osseointegration)

\subsubsection{Assessment of Osseointegration}

An implant is considered to be osseointegrated when an implant is in direct contact with the bone, and there is no relative movement between the implant and the bone. In other words, osseointegration is expressed clinically as longterm state of stability of the implant in the vital bone. According to Albrektsson (1985), a loaded implant is considered osseointegrated if the average surface contact with bone is a minimum of $50 \%$ [7]. Initially, the strength of the interface (initial stability) between bone and implant is high due to mechanical stability; however, it decreases over the next 
few weeks due to bone remodeling and then increases again due to new bone formation (secondary stability). The stability also depends on biophysical stimulation and the healing time. To clinically evaluate osseointegration mobility tests, standardized radiographs and Resonance Frequency Analysis (RFA) are used [6].

\subsubsection{Factors that Determine Osseointegration}

There are many factors that influence the formation and maintenance of bone at the implant surface $[3,6]$.

1. Biocompatibility of the implant material - Commercially pure titanium (CpTi) is widely used as an implant material as it is highly biocompatible, it has good resistance to corrosion and no toxicity on macrophages or fibroblasts and lacks inflammatory response in peri-implant tissues, and it is composed of an oxide layer and has the ability to repair itself by re-oxidation when damaged. Alloys of titanium such as Ti-6Al-4 V (Aluminum 6\% and Vanadium 4\%) and other Aluminum and Vanadium-free alloys of Titanium have been popularly used. Currently, a Ti-Zr alloy (Titanium 83-87\% and Zirconium 13-17\%) has been introduced, which has mechanical properties superior to those of CpTi and Ti-6Al-4 V [8].

2. Implant geometry - The shape of the implant determines the surface area available for stress transfer and the initial stability of the implant. Implants were previously available as cylinders, but currently, most implants come in screwshaped (threaded) designs. Threaded implants with a circular cross section provide easy surgical placement and provide a greater functional surface area. These implants provide initial rigid fixation and limit micromovement during wound healing. The shape of the thread alters the force transmitted to the bone; it can be square, V, or reverse buttress shaped. The thread depth increases the surface area of the implant. Length of the implant contributes to the overall surface area. Increasing the length within limits increases the bone to implant contact for an implant, which is essential for osseointegration. Shorter implants are recommended today only with strict selection criteria and preferably work well only when splinted with other implants. Considering the width of an implant, although a wider implant increases the surface area for osseointegration, width depends on factors related to the surgical site. Overall, the shorter and smaller diameter implants have lower survival rates than their longer or wider counterparts. Longer implants have been suggested to provide greater stability under lateral loading conditions [9].

3. Surface characteristics -With exposure to air, Ti and its alloys form an oxide layer on the surface $\left(\mathrm{TiO}_{2}\right)$. The oxide layer protects against corrosion and also helps in calcium and phosphate ion exchange at the surface. Surfaces were modified to increase microroughness and hence the surface area for osseointegration. The additive processes are Ti plasma spraying, hydroxyapatite coating, discrete crystalline deposition (DCD), and electrochemical anodization (to increase the $\mathrm{TiO}_{2}$ layer). These processes increased the surface area for bone contact with the implant surface, which increases the osseointegration. Subtractive processes to increase microroughness were also utilized in several implants to increase the microroughness, which also contributed to better osseointegration. Sandblasting, acid etching, and laser modification are some of the subtractive processes. Sandblasting produces a macrotexture, which is converted to a microtexture by acid etching. This surface promotes greater osseous contact at earlier time points compared to plasma-sprayed coated implants. Titanium surfaces were treated with fluoride, and this roughened the surface and demonstrated better bone anchorage, as compared to unmodified titanium surfaces [10]. Research is currently oriented toward making biomimetic implant surfaces that shorten healing times and provide better bone to implant contact [11].

4. Systemic factors - Irradiation of the region, osteoporosis, smoking, and diabetes although not absolute contraindications for implant placement can interfere with the normal healing process and osseointegration. Heavy smoking results in significantly lower success rates with oral implants [12]. The local site anatomy such as the amount of residual ridge for successful implant placement can also affect the outcome [13].

5. Surgical technique - The extent of tissue manipulation, thermal irritation by use of rotary instruments, and protocols for a surgical procedure can affect the outcome of osseointegration [14].

6. Occlusal load - During the initial healing phase, the absence of micromotion is critical for implant osseointegration. Based on the primary stability achieved, different protocols for loading are selected. The amount of force and timing of loading are critical for osseointegration [15].

\subsection{Comparison Between Implant and Tooth Surface [16]}

Figure 18.2a, b, and c show the differences between implants and tooth.

Implant prosthetics provide highly esthetic results that mimic the natural tooth; however, certain critical differences in the structure of the peri-implant tissues and periodontal structures exist. The lack of a periodontal ligament is the most striking difference; this absence means that the connec- 

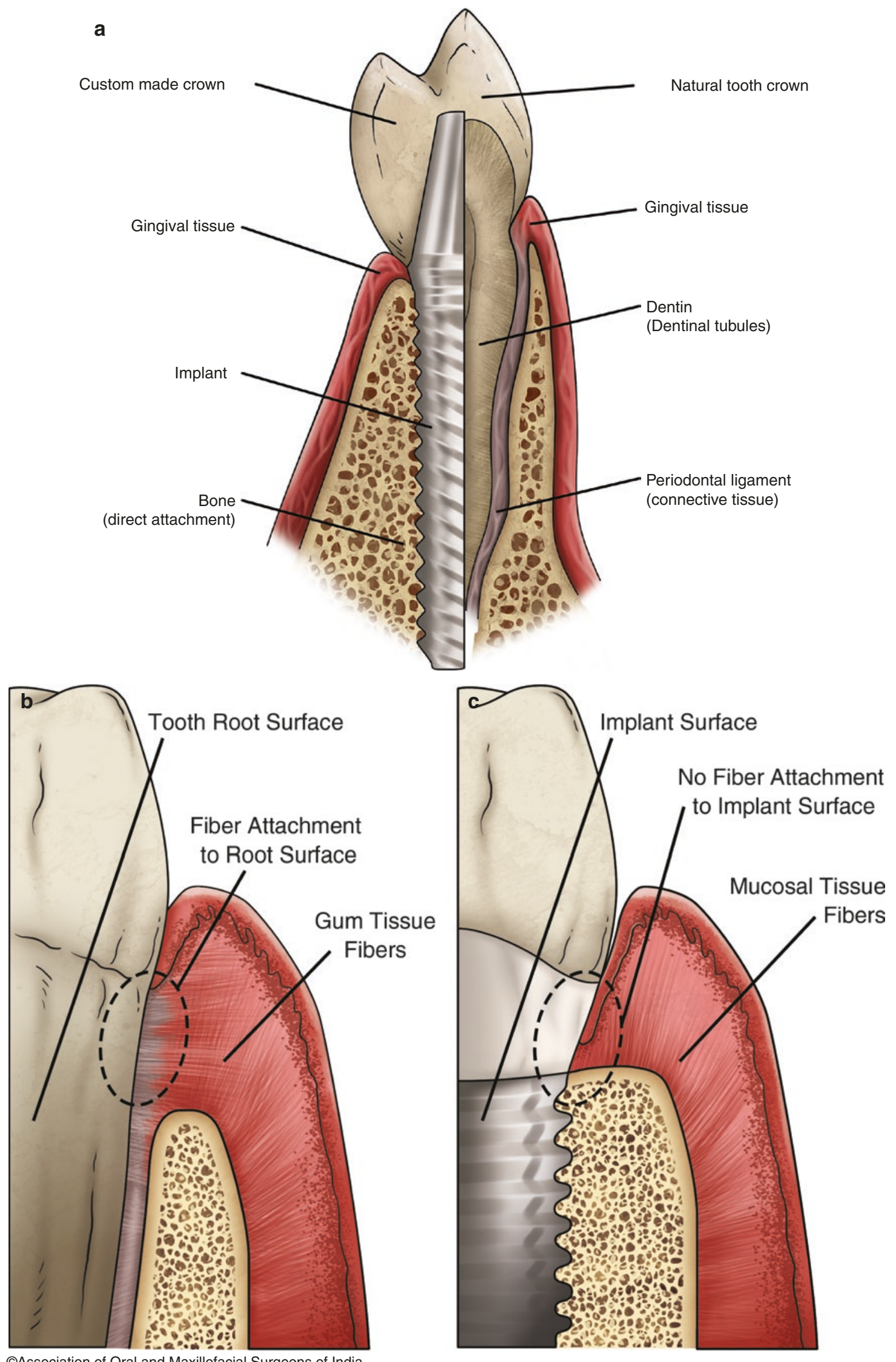

Fig. 18.2 (a, b, and $\mathbf{c})$ show diagrammatic representation of the biological differences between an implant and a tooth in longitudinal section 
tion between the implant and the surrounding bone is not as resilient as that around the tooth. Implants, unlike teeth, do not intrude or migrate to compensate for premature contacts, and hence, the repercussions of occlusal disharmony can be detrimental. Implants lack proprioception and reflex function due to the absence of the periodontal ligament. This is critical when implant-supported prosthesis opposes each other. Implants do not supraerupt with time and hence lead to occlusal disharmonies when used as replacements for young and growing individuals. Hence, any form of overload on an implant causes fracture in the prosthesis, the implant structure, or bone loss surrounding the implant.

\subsection{Types of implants}

(a) Based on the type of material:

(i) Pure titanium and titanium alloys:

Commercially pure titanium(CpTi) was the material of choice due to its high biocompatibility and resistance to corrosion. CpTi is available in Grades I to IV; however, to improve the mechanical properties, alloys of titanium such as Ti-6Al-4 V have been used. Several alloys with Ti, such as Ti-Au, Ti-In, Ti-Sn, Ti-Pb, Ti-Cu, and Ti-Nb, have been tested. A Ti-Zr alloy (Titanium $83-87 \%$ and Zirconium 13-17\%) is presently very popular as it has mechanical properties superior to those of the previously used alloys as well as high corrosion resistance.

(ii) Zirconia implants:

These implants are made from the oxide form of Zirconia $\left(\mathrm{ZnO}_{2}\right)$ and are "ceramic" implants that have high biocompatibility and ability to osseointegrate. In addition to the high mechanical properties, they were introduced especially for esthetic areas and in patients who maybe potentially allergic to titanium. The drawback of these implants is that most of the designs are one piece and only a few systems have two-piece implants. The idea of zirconia implants seems to be potential; however, no long-term evidence for its success exists at this time.

(b) Based on the shape:

(i) Screw-type implants:

Threads in screw-type implants increase the surface area for osseointegration. Threads help in stabilization by improving bone to implant contact and in stress distribution. There are several differences in thread shape, thickness, pitch, thread-face angle, etc. based on the manufacturers. These are the most widely used and documented form of implants.

(ii) Cylindrical and tapered implants:

Based on the shape of the implant body, implants are considered cylindrical (with parallel walls) or tapered. When the endosseous part of a cylindrical implant narrows in diameter toward the apex, an implant is considered tapered. The taper can be in the cervical, middle, or apical parts only or continuously taper from the cervical to the apex. Tapered implants were introduced to improve initial stability in less dense bone.

(iii) Platform switch implants:

When a smaller-diameter abutment is used on a larger-diameter implant collar, the implantabutment junction shifts inward toward the central axis of the implant. This is considered to be a major factor in limiting crestal bone resorption especially in esthetic sites.

(iv) Bone-level and tissue-level implants:

Tissue-level implants have a butt joint transition from the smooth collar to the rough portion, and this transition zone is placed almost level with the bony crest. This design is generally used for nonsubmerged healing; here, the implant-abutment microgap is away from the bony tissues. Bone-level implants have minimal/no smooth collar and are completely microrough, and they are inserted almost level with the bone. This is meant for submerged healing, and here, the implant-abutment microgap is adjacent to the bone crest. In these implants, platform switch is used to limit crestal bone resorption.

(c) Based on implant surface.

(i) Machined (Brånemark surface):

These are the minimally rough implant surfaces made of turned $\mathrm{CpTi}$, which were not further treated. These were used earlier and are also well documented. However, with a need to increase the surface area for bone attachment especially in less dense bone and to reduce time for osseointegration, these surfaces were modified. Smooth surfaces had an advantage of reduced attachment of plaque biofilms.

(ii) Textured/rough surfaces:

The smooth surfaces of the implants were altered to a textured surface to increase the surface area for osseointegration. They were classified as macro-, micro-, and nano-sized topologies based on the scale of roughness [17, 18]. Macrotopographic profiles of dental implants had 
a surface roughness in the range of millimeters to microns. This roughness was directly related to geometry of the implant, threaded screw, and macroporous surface treatment. Microrough topographies were in the range of 1 and $10 \mu \mathrm{m}$. A profile roughness average of $1-2 \mu \mathrm{m}$ is optimal for osseointegration [19]. The surfaces were altered by different processes. Additive processes resulted in these popular types-sintered porous surfaces, titanium plasma sprayed, and hydroxyapatite plasma sprayed. Subtractive processes also created a rough texture, and they were sandblasting, acid etching, and laser alteration. Rough surfaces were demonstrated to have better bone to implant contact, which resulted in better osseointegration $[20,21]$. Over the years, nanotopographies have been explored. Compaction of nanoparticles (such as titanium dioxide), molecular self-assembly method, and acid/alkali treatments or peroxidation for nanoparticle deposition have been advocated to increase nanoroughness.

(iii) Hydrophobic and hydrophilic implant surfaces [22]:

Initially, modification of implant surfaces concentrated on surface topography, and hence, the surfaces were hydrophobic. It was observed that porous devices should have a hydrophilic surface to induce the adsorption of bodily fluids into small pores and cavities of the structure. The surface chemistry of implants was altered to allow for hydrophilicity, and these surfaces have enhanced bone apposition during the initial phases of healing [23].

(d) Based on length (Al-Johany 2017) [24].

(i) Extra-short: $6 \mathrm{~mm}$ in length or less.

(ii) Short: From more than $6 \mathrm{~mm}$ to less than $10 \mathrm{~mm}$.

(iii) Standard: From $10 \mathrm{~mm}$ to less than $13 \mathrm{~mm}$.

(iv) Long: More than $13 \mathrm{~mm}$.

Although traditionally, the concept was to get implants "as long as possible" for good osseointegration, the current trend with improved surfaces is "as long as needed". The introduction of shorter implants is to reduce the invasiveness and reduce morbidity.

(e) Based on diameter (Al-Johany 2017) [24].

(i) Extra narrow: Less than $3.0 \mathrm{~mm}$.

(ii) Narrow: From $3.0 \mathrm{~mm}$ to less than $3.75 \mathrm{~mm}$.

(iii) Standard: From $3.75 \mathrm{~mm}$ to less than $5 \mathrm{~mm}$.

(iv) Wide: $5.0 \mathrm{~mm}$ or more.

Earlier, implants with diameters as wide as the tooth being replaced were used. Changing concepts of jumping gap, preserving the buccal cortical plate, and optimal 3-dimensional position coupled with improved surfaces encouraged slightly narrow diam-
Box 18.1 Types of Implants

Implants can be classified as follows:

(a) Implant Material

(i) Titanium and titanium alloys

(ii) Zirconia

(b) Shape:

(i) Screw type implants

(ii) Cylindrical, apically tapered, and fully tapered

(iii) Platform-switch implants

(iv) Bone level vs. tissue level implants

(c) Implant surface

(i) Machined (Brånemark surface)

(ii) Textured/rough surfaces

(iii) Hydrophobic/Hydrophilic surfaces

(d) Implant length

(e) Implant diameter

eters as compared to previous trends. Extra-narrow and narrow-diameter implants are used in deficient sites to minimize invasiveness and morbidity.

\subsection{Preoperative Examination of Potential Implant Patients}

\subsubsection{Clinical Examination}

Before implant treatment, a careful analysis should be conducted. This includes patient's current health status and medications and details of past medical history and medical treatments.

Patients should be questioned about parafunctional habits, oral hygiene, and personal habits such as tobacco, alcohol, and drugs. The compliance, motivation, attitude, understanding, and expectations of the patient are important for optimal treatment outcome.

Clinical examination should include extra-oral examination, i.e., lip line, lip competence, and temporomandibular joint. Intraoral assessment should include assessment of the edentulous space, occlusion, status of adjacent and opposing teeth, overall periodontal status, presence of other implants and restorations, shape of the teeth, gingival biotype, and any other local factor that may impact the success of the treatment.

Diagnostic study models and intraoral clinical photographs are essential for documentation as well as for the further assessment of spatial and occlusal relationships. 

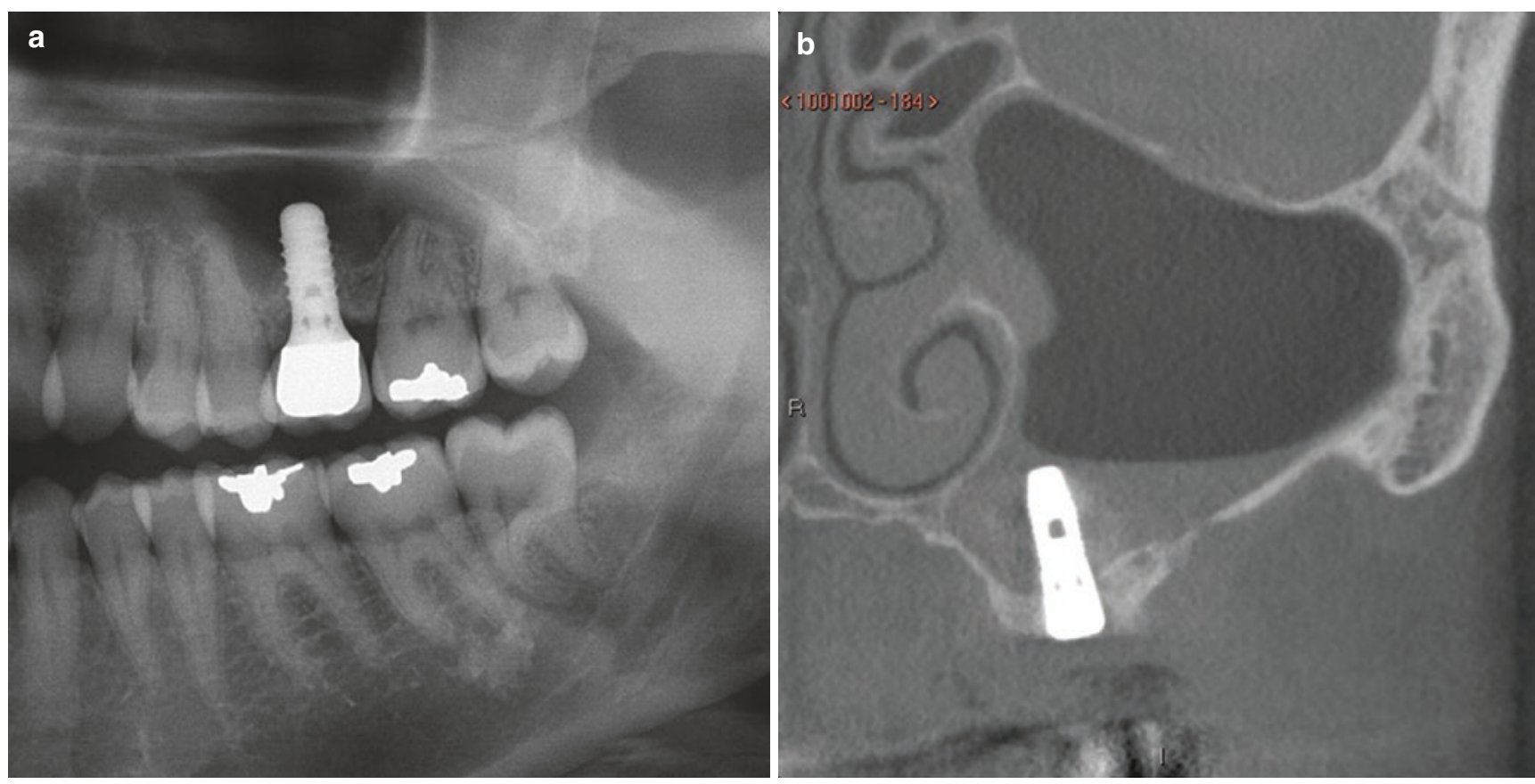

CAssociation of Oral and Maxillofacial Surgeons of India

Fig. 18.3 (a and $\mathbf{b}$ ) show examples of two-dimensional and 3-dimensional examination of an implant placed with sinus floor elevation

\subsubsection{Radiographic Examination}

Figure 18.3a and b show examples of two-dimensional and 3-dimensional examination of the maxillary sinus.

Radiographic examination should be done in the evaluation phase to determine the status and anatomy of the underlying bone, if implant placement is possible and if any other surgical procedures are required before implant placement. A 2-dimensional radiograph of the area is desired; however, this is insufficient to provide a detailed 3-dimensional assessment of the site. Hence, the radiograph of choice is the Cone Beam Computerized Tomography (CBCT) as it provides a detailed three-dimensional analysis of the edentulous area along with the neighboring anatomical structures. With the software for CBCT, it is possible to measure accurately the dimension of the site and distances from critical structures and accurately plan which implant dimension would be appropriate. CBCT imaging also gives us information on which sites require augmentation and if so the location and extent required.

\subsubsection{Correct 3-Dimensional Position for an Implant}

For the site of implant placement, the available space should be evaluated in three dimensions, i.e., mesiodistal, buccolin- gual, and apicocoronal dimensions. A graduated periodontal probe can be used for clinical measurements; however, this information is best recorded from imaging techniques such as CBCT. While evaluating the available space, factors such as proximity to adjacent anatomical structures such as maxillary sinus, mandibular nerve, nasal floor, adjacent tooth roots, etc. should be considered.

The minimal space required for an implant depends on the size of the implant to be used (in terms of length and diameter), whether the implant is placed adjacent to two natural teeth or adjacent to an implant and the apicocoronal distance in the bone.

1. Implant adjacent to a natural tooth: Buser et al. (2004) suggested a concept for correct 3-dimensional implant placement [25]. They designated zones called as comfort zones (which is the ideal position for an implant) and danger zones (in which implants should not be placed). This was defined in three directions mesiodistally, coronoapically, and orofacially. (Figure $18.4 \mathrm{a}, \mathrm{b}$, and $\mathrm{c}$ show diagrammatic representation of the correct positioning of implants in a 3 -dimensional manner). The ideal mesiodistal distance between a natural tooth and the shoulder of an implant is $1.5 \mathrm{~mm}$ [25]. The zone up to $1-1.5 \mathrm{~mm}$ from the adjacent teeth on either side was the danger zone. Between the danger zone was the comfort zone that is safe for implant placement [25]. For 
example, if an implant of $4.1 \mathrm{~mm}$ in diameter is placed between two natural teeth, the minimum mesiodistal distance available should be $7 \mathrm{~mm}$ (to allow $1.5 \mathrm{~mm}$ between the implant and the natural teeth on either side).
If placed too close to the adjacent teeth, it causes bone loss. In the orofacial dimension, the implant shoulder is positioned palatal to the incisal edge of the future restoration (or $1 \mathrm{~mm}$ palatal to the point of emergence of the

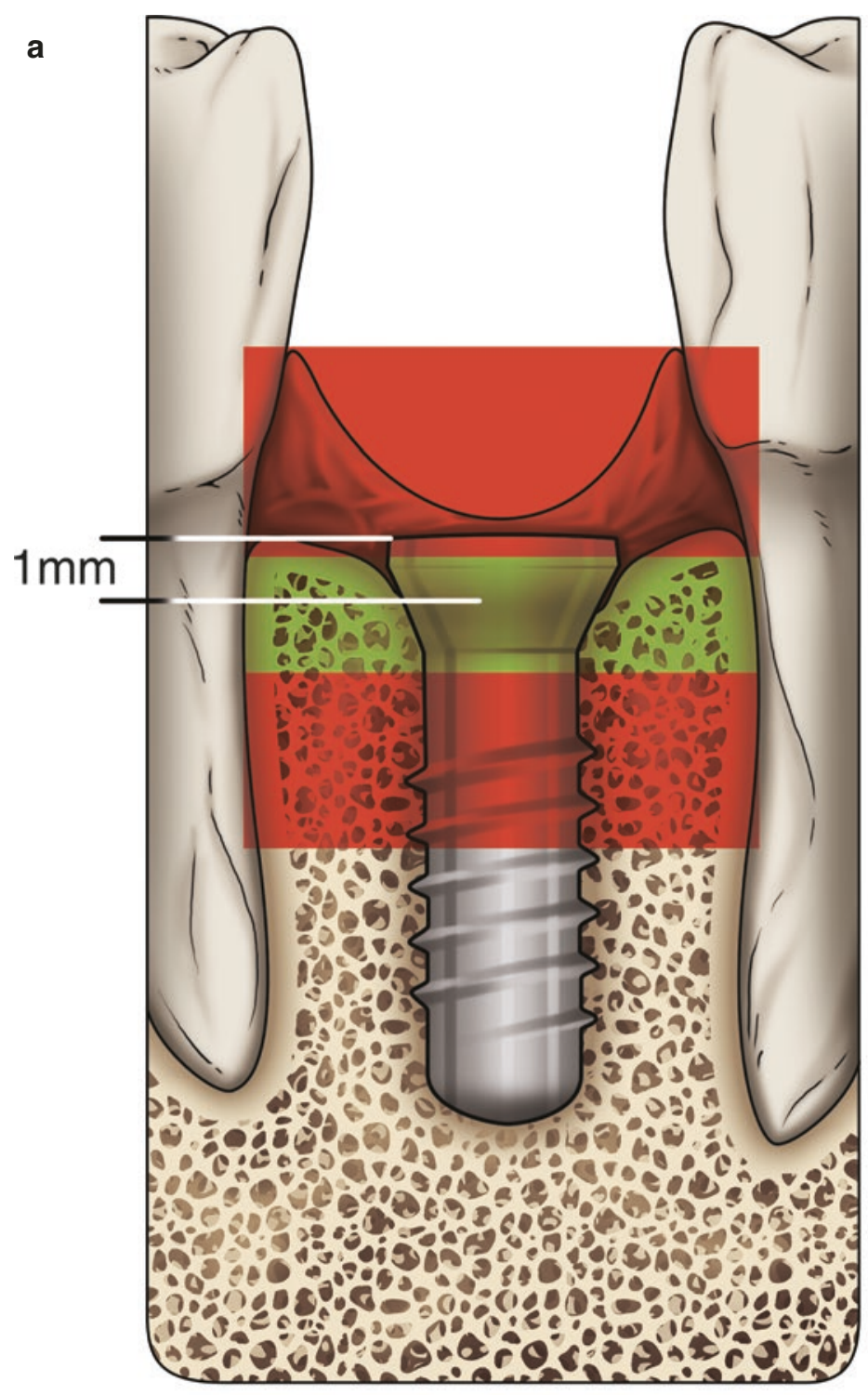

Corono Apically

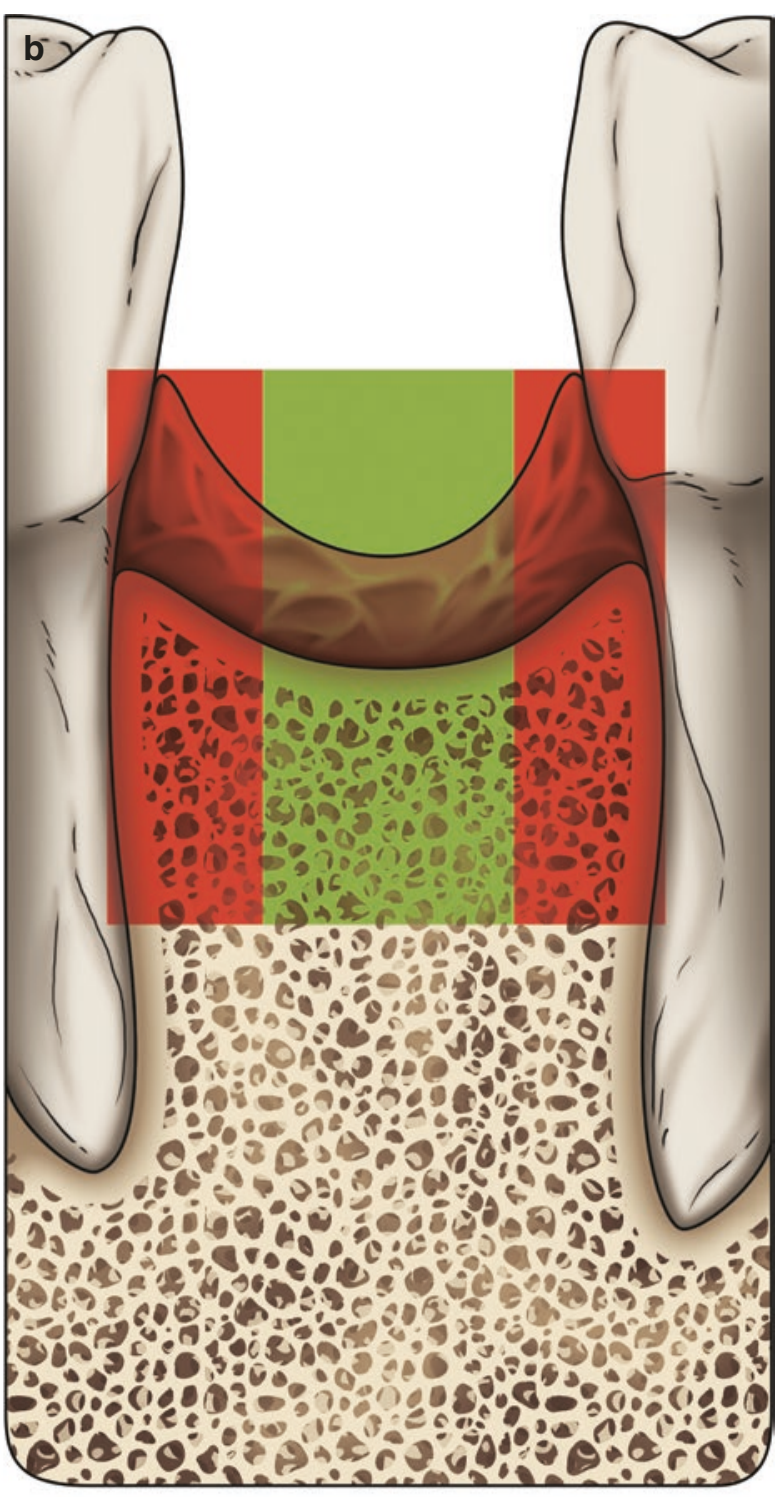

Mesio Distally

\section{Comfort Zone -}

\section{Danger Zone -}

Fig. 18.4 (a, $\mathbf{b}$, and $\mathbf{c})$ diagrammatic representation of ideal placement of a single implant in green shadow and unideal positions that could lead to complications (in red shadow). (a) ideal coronoapical position, (b) ideal mesiodistal position, and (c) ideal orofacial position 


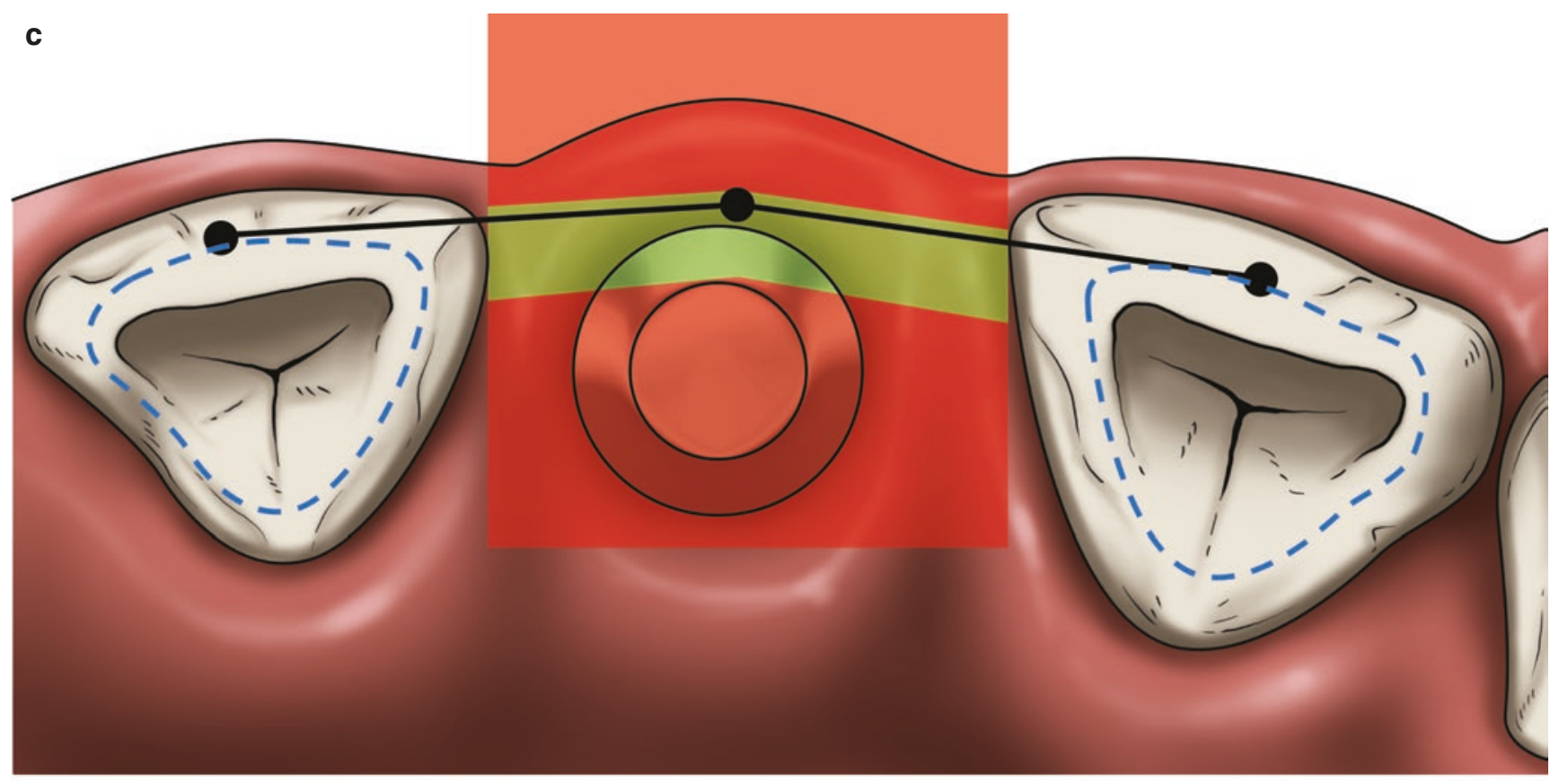

\section{Comfort Zone -}

\section{Danger Zone -}

CAssociation of Oral and Maxillofacial Surgeons of India

Fig. 18.4 (continued)

adjacent teeth). The oral aspect has a danger zone as well, indicating that an implant should not be placed too far orally to prevent the use of a ridge lap restoration. Too far facially will result in increased mucosal recession. In the apicocoronal direction, the apex of the implant should be at least 1-2 mm away from any anatomical structure such as nerve, sinus, or tooth roots. Also, in the shoulder of the future implant should be at least $1 \mathrm{~mm}$ apical to the cementoenamel junction of the adjacent teeth to allow for a proper emergence profile [25]. Placing an implant too deep will result in too much countersinking, difficult handling, and facial mucosal recession. Placing an implant too superficially will cause the metal margin to be visible and improper emergence profile. In addition to this, the ideal facial bone thickness should be $2 \mathrm{~mm}$ [26] and the lingual bone thickness should be $1.5 \mathrm{~mm}$. Hence, for a $4.1 \mathrm{~mm}$ implant, minimum orofacial distance should be approximately $7.5 \mathrm{~mm}$. Also, to prevent the appearance of black triangles, the apicocoronal distance from the interdental contact point to the crest of bone should not exceed $5 \mathrm{~mm}$. (Figure 18.5a shows diagrammatic repre- sentation of the distance between interdental contact point and the crest of bone, for adequate papilla preservation).

2. Implants adjacent to each other: The mesiodistal distance between the implants should be at least $3 \mathrm{~mm}[25,26]$. This is critical to allow adequate interimplant bone and hence the formation of a soft tissue papilla overlying the bone. The other requisites for mesiodistal, orofacial, and apicocoronal dimensions, as previously mentioned, apply in addition. (Figure 18.5b shows diagrammatic representation of the distance between interdental contact point and the crest of bone, for adequate papilla preservation).

When the space for an implant of a particular diameter is less than ideal, a decision should be made either to augment the site with bone or to choose an implant of smaller diameter. However, this decision requires clinical expertise as augmentation procedures are technique sensitive and using smaller diameter implants depends on evaluation of the occlusal forces in the area. The interocclusal distance also needs to be evaluated prior to implant placement as it determines the choice of prosthetic rehabilitation of the implant. If the interocclusal distance is reduced, 


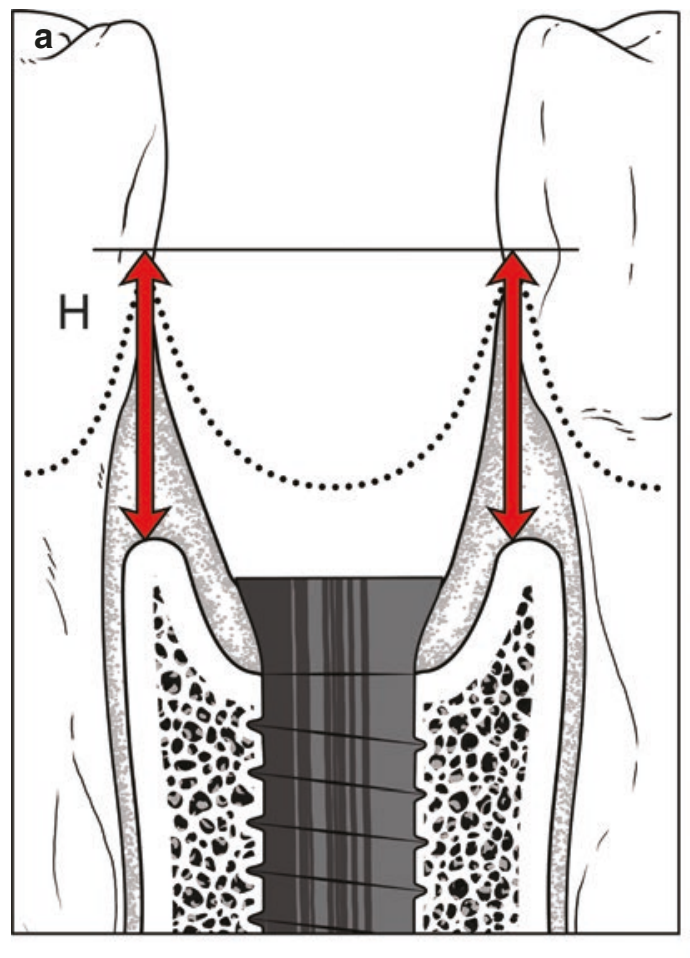

Critical Dimension : $\mathrm{H}<5 \mathrm{~mm}$

(C)Association of Oral and Maxillofacial Surgeons of India

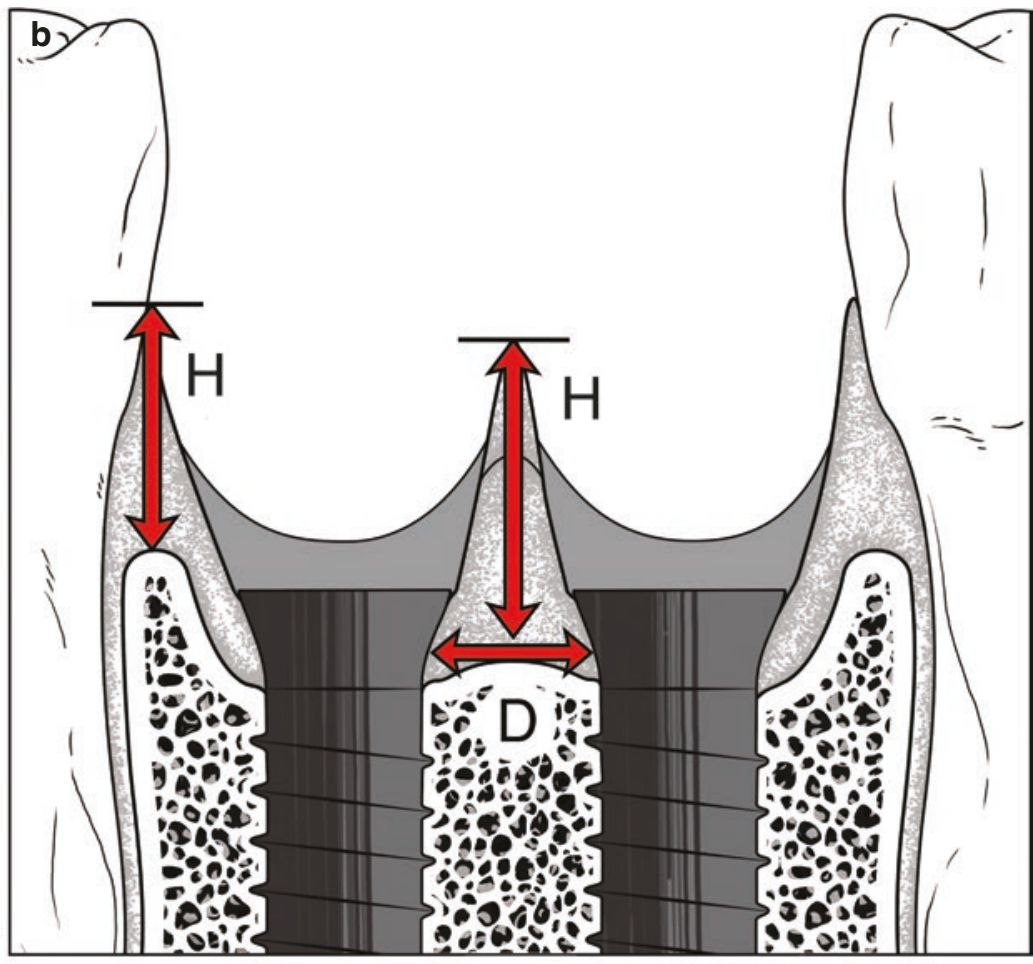

Critical Dimensions: $\quad H<5 \mathrm{~mm} \quad D>3 \mathrm{~mm}$
Fig. 18.5 (a and b) diagrammatic representation of the critical dimensions in implant placement in relation to interdental papilla. (a) The height $(\mathrm{H})$ of the interdental contact from the crest of the interdental alveolar bone should not be more than $5 \mathrm{~mm}$ for obtaining adequate

the choice would be to use a screw-retained prosthesis over a cement-retained one. Screw-retained prosthesis, however, is the more preferred technique due to ease in retrievability and cleansability.

The amount of keratinized tissue in the site should also be evaluated before surgery as this determines the location of the incision. Ideally, a band of at least $2 \mathrm{~mm}$ (minimum $1 \mathrm{~mm}$ ) keratinized tissue should surround the implant, and this is critical to the long-term success of the implant. If this is not achievable, procedures to augment the keratinized mucosa should be planned. Keratinized mucosa is necessary as it provides a physical barrier to oral plaque and to the forces of mastication as compared to nonkeratinized mucosa [27].

\subsection{SAC Classification}

The International Team for Implantology (ITI) proposed a classification of sites for implant placement based on the analysis of several factors [28].

Based on these factors, sites for implant surgery could be classified as straightforward (S), advanced (A), and complex (C). interdental papillary morphology. (b) The interimplant distance (D) should be at least $3 \mathrm{~mm}$ for obtaining adequate interdental papillary morphology

This provides the clinician an assessment of the site for implant placement before the surgery is planned and is based on the level of expertise of the clinician who can either treat or refer to a specialist.

The determinants of the classification are.

1. Esthetic or nonesthetic site: Any case in the esthetic zone or has an esthetic risk should be considered as advanced or complex.

2. Complexity of the process: The level of complexity can be assessed by considering the number of steps and the number of areas in which an acceptable outcome has to be achieved.

3. Risk of complications: The SAC Classification can be used to identify and quantify risks for complications. This allows pretreatment planning to control and minimize risks.

The general modifying factors are.

1. Clinical competence and expertise: The SAC Classification for a case type is independent of the clinician's skill and competence. A Straightforward case is an uncomplicated 
procedure, and a Complex case is the one that is difficult to manage.

2. Compromised patient's health: Patients with risk factors such as smoking, diabetes, irradiated bone, history of periodontal disease, poor oral hygiene, and bruxism need to be monitored as they have a higher risk for complications.

3. Growth considerations: Implants placed in the jaws of growing individuals are modifying factors as they present esthetic and functional issues.

4. Iatrogenic factors: Suboptimal planning and treatment outcomes increase the difficulty in the implant treatment phase. For example, incorrect three-dimensional implant placement will complicate the restorative process.

Tables 18.1, 18.2, and 18.3 show the esthetic, surgical, and restorative modifying factors to be considered during implant treatment planning and execution.

Table 18.1 The esthetic modifying factors are determined by the Esthetic Risk Assessment (ERA)

\begin{tabular}{|c|c|c|c|}
\hline \multirow[t]{2}{*}{ Esthetic factors } & \multicolumn{3}{|l|}{ Level of risk } \\
\hline & Low & Medium & High \\
\hline Medical status & $\begin{array}{l}\text { Healthy and } \\
\text { co-operative patient } \\
\text { with an intact } \\
\text { immune system. }\end{array}$ & - & $\begin{array}{l}\text { Reduced } \\
\text { immune } \\
\text { system }\end{array}$ \\
\hline $\begin{array}{l}\text { Patients' } \\
\text { esthetic } \\
\text { expectation }\end{array}$ & Low & Medium & High \\
\hline Smoking habit & Nonsmoker & $\begin{array}{l}\text { Light smoker } \\
(<10 \text { cigs/day) }\end{array}$ & $\begin{array}{l}\text { Heavy } \\
\text { smoker (>10 } \\
\text { cigs/day) }\end{array}$ \\
\hline Lip line & Low & Medium & High \\
\hline $\begin{array}{l}\text { Shape of tooth } \\
\text { crowns }\end{array}$ & Rectangular & & Triangular \\
\hline $\begin{array}{l}\text { Gingival } \\
\text { biotype }\end{array}$ & $\begin{array}{l}\text { Low scalloped and } \\
\text { thick }\end{array}$ & $\begin{array}{l}\text { Medium } \\
\text { scalloped and } \\
\text { medium thick }\end{array}$ & $\begin{array}{l}\text { High } \\
\text { scalloped } \\
\text { and thin }\end{array}$ \\
\hline $\begin{array}{l}\text { Bone anatomy } \\
\text { of alveolar crest }\end{array}$ & $\begin{array}{l}\text { Alveolar crest } \\
\text { without bone } \\
\text { deficiency }\end{array}$ & $\begin{array}{l}\text { Horizontal } \\
\text { bone } \\
\text { deficiency }\end{array}$ & $\begin{array}{l}\text { Vertical bone } \\
\text { deficiency }\end{array}$ \\
\hline $\begin{array}{l}\text { Bone level at } \\
\text { adjacent teeth }\end{array}$ & $\begin{array}{l}\leq 5 \mathrm{~mm} \text { to contact } \\
\text { point }\end{array}$ & $\begin{array}{l}5.5 \text { to } 6.5 \mathrm{~mm} \\
\text { to contact } \\
\text { point }\end{array}$ & $\begin{array}{l}\geq 7 \mathrm{~mm} \text { to } \\
\text { contact point }\end{array}$ \\
\hline $\begin{array}{l}\text { Soft tissue } \\
\text { anatomy }\end{array}$ & Intact soft tissue & & $\begin{array}{l}\text { Soft tissue } \\
\text { defects }\end{array}$ \\
\hline $\begin{array}{l}\text { Width of } \\
\text { edentulous span }\end{array}$ & 1 tooth $(\geq 7 \mathrm{~mm})$ & $\begin{array}{l}1 \text { tooth } \\
(\leq 7 \mathrm{~mm})\end{array}$ & $\begin{array}{l}2 \text { teeth or } \\
\text { more }\end{array}$ \\
\hline $\begin{array}{l}\text { Restorative } \\
\text { status of } \\
\text { neighboring } \\
\text { teeth }\end{array}$ & Virgin & & Restored \\
\hline $\begin{array}{l}\text { Infection at } \\
\text { implant site }\end{array}$ & None & Chronic & Acute \\
\hline
\end{tabular}

Adapted with permission from Dawson A, Chen S, Buser D, Cordaro L, Martin W, Belser U. The SAC Classification in Implant Dentistry. Editors: Dawson A, Chen S. Quintessence Publishing Co. Ltd. 2009
The above-mentioned modifiers have to be considered for every implant case during the assessment and planning phase of treatment. Risks can be identified prior to treatment, thus minimizing complications. To classify as Straightforward, Advanced, or Complex for a specific case, the specific features of the case can be matched with the descriptions in the tables. The level that best matches the factors of the individual case will provide the SAC Classification for that case.

The final treatment plan including additional surgical procedures (if required) should be formulated after accurate diagnosis and consideration of the patient's systemic and local factors, bearing in mind the requirements of the patient.

Table 18.2 Surgical modifying factors

\begin{tabular}{|c|c|c|c|}
\hline \multirow[t]{2}{*}{ Site factors } & \multicolumn{3}{|c|}{ Risk or degree of difficulty } \\
\hline & Low & Moderate & High \\
\hline \multicolumn{4}{|l|}{ Anatomic risk } \\
\hline $\begin{array}{l}\text { Proximity to } \\
\text { vital anatomic } \\
\text { structures }\end{array}$ & $\begin{array}{l}\text { Minimal risk } \\
\text { of } \\
\text { involvement }\end{array}$ & $\begin{array}{l}\text { Moderate risk of } \\
\text { involvement }\end{array}$ & $\begin{array}{l}\text { High risk of } \\
\text { involvement }\end{array}$ \\
\hline \multicolumn{4}{|l|}{ Bone volume } \\
\hline Horizontal & Adequate & $\begin{array}{l}\text { Deficient, but } \\
\text { allowing } \\
\text { simultaneous } \\
\text { augmentation }\end{array}$ & $\begin{array}{l}\text { Deficient, } \\
\text { requiring prior } \\
\text { augmentation }\end{array}$ \\
\hline Vertical & Adequate & $\begin{array}{l}\text { Small deficiency } \\
\text { crestally, requiring } \\
\text { slightly deeper } \\
\text { coronoapical } \\
\text { implant position. } \\
\text { Small deficiency } \\
\text { apically due to } \\
\text { proximity to } \\
\text { anatomical } \\
\text { structures, requiring } \\
\text { shorter than } \\
\text { standard implant } \\
\text { lengths. }\end{array}$ & $\begin{array}{l}\text { Deficient, } \\
\text { requiring prior } \\
\text { augmentation }\end{array}$ \\
\hline \multicolumn{4}{|l|}{ Esthetic risk } \\
\hline Esthetic zone & No & & Yes \\
\hline Biotype & Thick & & Thin \\
\hline $\begin{array}{l}\text { Thickness of } \\
\text { facial bone } \\
\text { wall }\end{array}$ & $\begin{array}{l}\text { Sufficient } \\
\geq 1 \mathrm{~mm}\end{array}$ & & $\begin{array}{l}\text { Insufficient } \\
<1 \mathrm{~mm}\end{array}$ \\
\hline \multicolumn{4}{|l|}{ Complexity } \\
\hline $\begin{array}{l}\text { Number of } \\
\text { prior or } \\
\text { simultaneous } \\
\text { procedures }\end{array}$ & $\begin{array}{l}\text { Implant } \\
\text { placement } \\
\text { without } \\
\text { adjunctive } \\
\text { procedures }\end{array}$ & $\begin{array}{l}\text { Implant placement } \\
\text { with simultaneous } \\
\text { procedures }\end{array}$ & $\begin{array}{l}\text { Implant } \\
\text { placement } \\
\text { with staged } \\
\text { procedures }\end{array}$ \\
\hline \multicolumn{4}{|l|}{ Complications } \\
\hline $\begin{array}{l}\text { Risk of } \\
\text { surgical } \\
\text { complications }\end{array}$ & Minimal & Moderate & High \\
\hline $\begin{array}{l}\text { Consequences } \\
\text { of } \\
\text { complications }\end{array}$ & $\begin{array}{l}\text { No adverse } \\
\text { effect }\end{array}$ & $\begin{array}{l}\text { Suboptimal } \\
\text { outcome }\end{array}$ & $\begin{array}{l}\text { Severely } \\
\text { compromised } \\
\text { outcome }\end{array}$ \\
\hline
\end{tabular}

Adapted with permission from Dawson A, Chen S, Buser D, Cordaro L, Martin W, Belser U. The SAC Classification in Implant Dentistry. Editors: Dawson A, Chen S. Quintessence Publishing Co. Ltd. 2009 
Table 18.3 Restorative modifiers: These are the restorative factors that influence the SAC classification

\begin{tabular}{|c|c|c|c|c|}
\hline \multirow[b]{2}{*}{ Issue } & \multirow[b]{2}{*}{ Notes } & \multicolumn{3}{|l|}{ Degree of difficulty } \\
\hline & & Low & Moderate & High \\
\hline \multicolumn{5}{|l|}{ Oral environment } \\
\hline General oral health & & No active disease & & Active disease \\
\hline $\begin{array}{l}\text { Condition of adjacent } \\
\text { teeth }\end{array}$ & & Restored teeth & & Virgin teeth \\
\hline Reason for tooth loss & & Caries/trauma & & $\begin{array}{l}\text { Periodontal disease or } \\
\text { occlusal parafunction }\end{array}$ \\
\hline \multicolumn{5}{|l|}{ Occlusion } \\
\hline Occlusal scheme & & Anterior guidance & & No guidance \\
\hline $\begin{array}{l}\text { Involvement in } \\
\text { occlusion }\end{array}$ & $\begin{array}{l}\text { The degree to which the implant } \\
\text { prosthesis is involved in the patient's } \\
\text { occlusal scheme }\end{array}$ & Minimal involvement & & $\begin{array}{l}\text { Implant restoration is } \\
\text { involved in guidance }\end{array}$ \\
\hline Occlusal parafunction & $\begin{array}{l}\text { Risk of complication to the restoration, } \\
\text { but not to implant survival }\end{array}$ & Absent & & \\
\hline \multicolumn{5}{|l|}{ Restorative volume } \\
\hline Interarch distance & $\begin{array}{l}\text { Refers to the distance from the proposed } \\
\text { implant restorative margin to the } \\
\text { opposing occlusion }\end{array}$ & $\begin{array}{l}\text { Adequate for planned } \\
\text { restoration }\end{array}$ & $\begin{array}{l}\text { Restricted space, but } \\
\text { can be managed }\end{array}$ & $\begin{array}{l}\text { Adjunctive therapy will be } \\
\text { necessary to gain sufficient } \\
\text { space for the planned } \\
\text { restoration }\end{array}$ \\
\hline Mesiodistal space & $\begin{array}{l}\text { The arch length available to fit tooth } \\
\text { replacements }\end{array}$ & $\begin{array}{l}\text { Sufficient to fit } \\
\text { replacements for } \\
\text { missing teeth }\end{array}$ & $\begin{array}{l}\text { Some reduction in } \\
\text { size or number of } \\
\text { teeth will be } \\
\text { necessary }\end{array}$ & $\begin{array}{l}\text { Adjunctive therapy will be } \\
\text { needed to achieve a } \\
\text { satisfactory result }\end{array}$ \\
\hline Span of restoration & & Missing tooth & $\begin{array}{l}\text { Extended edentulous } \\
\text { space }\end{array}$ & Full arch \\
\hline $\begin{array}{l}\text { Volume and } \\
\text { characteristics of the } \\
\text { edentulous saddle }\end{array}$ & $\begin{array}{l}\text { Refers to whether there is sufficient tissue } \\
\text { volume to support the final restoration, or } \\
\text { some prosthetic replacement of soft } \\
\text { tissues will be necessary }\end{array}$ & $\begin{array}{l}\text { No prosthetic } \\
\text { soft-tissue } \\
\text { replacement will be } \\
\text { necessary }\end{array}$ & & $\begin{array}{l}\text { Prosthetic replacement of } \\
\text { soft tissue will be needed } \\
\text { for esthetics or phonetics }\end{array}$ \\
\hline $\begin{array}{l}\text { Provisional } \\
\text { restorations }\end{array}$ & & & & Present \\
\hline $\begin{array}{l}\text { During implant } \\
\text { healing }\end{array}$ & & Not required & & Fixed \\
\hline $\begin{array}{l}\text { Implant supported } \\
\text { provisionals needed }\end{array}$ & $\begin{array}{l}\text { Provisional restorations will be needed to } \\
\text { develop esthetics and soft tissue transition } \\
\text { zones }\end{array}$ & Not required & $\begin{array}{l}\text { Restorative margin } \\
<3 \mathrm{~mm} \text { apical to } \\
\text { mucosal crest }\end{array}$ & $\begin{array}{l}\text { Restorative margin }>3 \mathrm{~mm} \\
\text { apical to mucosal crest }\end{array}$ \\
\hline $\begin{array}{l}\text { Materials/ } \\
\text { manufacture }\end{array}$ & $\begin{array}{l}\text { Materials and techniques used in the } \\
\text { manufacture of definitive prostheses }\end{array}$ & $\begin{array}{l}\text { Resin-based materials } \\
\pm \text { metal reinforcement }\end{array}$ & $\begin{array}{l}\text { Porcelain fused to } \\
\text { metal }\end{array}$ & \\
\hline Loading protocols & $\begin{array}{l}\text { To date, immediate restoration and } \\
\text { loading procedures are lacking scientific } \\
\text { documentation }\end{array}$ & $\begin{array}{l}\text { Conventional or early } \\
\text { loading }\end{array}$ & & Immediate loading \\
\hline Maintenance needs & $\begin{array}{l}\text { Anticipated maintenance needs based on } \\
\text { patient presentation and the planned } \\
\text { prosthesis }\end{array}$ & Low & Moderate & High \\
\hline
\end{tabular}

Adapted with permission from Dawson A, Chen S, Buser D, Cordaro L, Martin W, Belser U. The SAC Classification in Implant Dentistry. Editors: Dawson A, Chen S. Quintessence Publishing Co. Ltd. 2009

\subsection{Implant Solutions for Different Edentulous Situations}

Implants can be used as replacement options for all kinds of edentulous situations varying from single tooth gaps to completely edentulous jaws (Figure 18.6 shows an example where an implant has been used for the restoration of single tooth, and $7 \mathrm{~b}$ shows an example where implants have been used for the replacement of the edentulous upper and lower jaws). The treatment plan varies in complexity as the number of teeth replacements increases, if it is an esthetic site or not and if the opposing dentition is implant-supported or not and depending on the occlusal load. As few as possible but as many as needed should be the key when placing implants. The selection of the size of the implant (length and width) and the number of implants especially in areas of poor bone quality is important for providing the correct solution.

For large edentulous spans, it is preferable to use as many implants as required, to support the occlusal forces in that area. Cantilever prosthesis on implants has to be used with discretion and is limited to areas of low occlusal demand. It is not preferable to splint implant with natural teeth as 

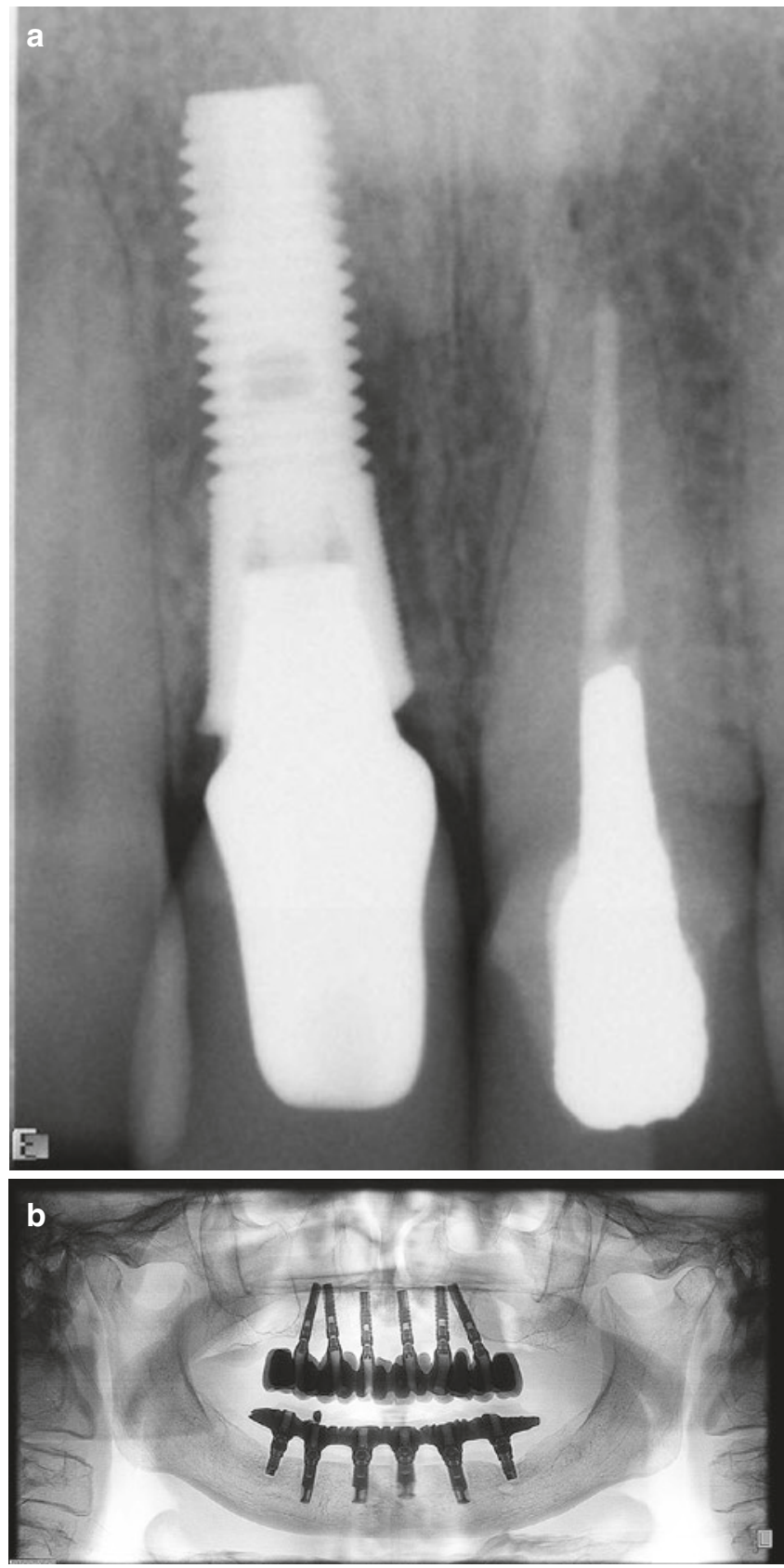

CAssociation of Oral and Maxillofacial Surgeons of India

Fig. 18.6 (a) shows an example where an implant has been used for the restoration of single tooth, and (b) shows an example where implants have been used for the replacement of the edentulous upper and lower jaws

implants cannot intrude with force like natural teeth. Longspan bridges on implants are not advisable in soft bone, e.g., in the completely edentulous maxilla, a fixed prosthesis can be given on six implants, while in the mandible, the same can be achieved with only four implants. For removable prosthesis, in an edentulous maxilla, four to six are sufficient, while in the edentulous mandible, the similar prosthetic solution can be achieved with two to four implants. There are several concepts of implant replacement for long edentulous spans and several designs of implants indicated for specific types of sites; however, the details of these are beyond the scope of this chapter.

\subsection{Timing of Implant Placement Postextraction}

\subsubsection{Hard and Soft Tissue Alterations Postextraction}

Studies in beagle dog revealed that postextraction, the bundle bone resorbs as the blood supply to this bone is compromised due to tooth extraction $[29,30]$. This results in vertical bone loss in both facial and lingual walls of the socket, but it is more pronounced on the facial aspect as most often it is thinner in width than the lingual wall [30]. In human studies, ridge width reduction of up to $50 \%$ occurred during the first year after tooth loss in premolar and molar sites, and twothirds of the total change took place within the first 3 months following extraction [31]. Dimensional alterations occurred in both height and width, with approximately $2.6-4.5 \mathrm{~mm}$ in width and $0.4-3.9 \mathrm{~mm}$ in height being lost in the healed sockets [32]. Histologically, the density of vascular structures and macrophages reduced from 2 to 4 weeks, the osteoclastic activity slowly decreased over a 4-week period, and osteoblasts peaked at 6-8 weeks remaining almost stable thereafter [33]. Thin facial walls seem to be prone for resorption, and sites with facial bone wall thickness of $1 \mathrm{~mm}$ or less had vertical bone loss of $7.5 \mathrm{~mm}(62 \%)$ of the original bone height after an 8 week healing period. Patients with thick wall phenotype, having facial bone wall thickness of more than $1 \mathrm{~mm}$, had only about $1.1 \mathrm{~mm}(9 \%)$ vertical bone loss [34]. Also, for single extraction sites, the dimensional alteration occurred mainly in the central mid-facial area of the socket wall, while the proximal areas that had viable periodontal ligament of the adjacent teeth remained nearly unchanged after flapless tooth extraction at 8 weeks of healing [35]. With this pattern of resorption, a thin wall phenotype will develop a two-wall defect, while a thick-wall phenotype will result in a three-wall defect after initial remodeling [34]. Thus, the evaluation of facial wall thickness is critical to predict the future of bone loss prior to extraction [13]. With the above findings related to the pattern of bone remodeling and the timing of the cellular activity, in thin bone wall phenotypes, it is recommended to allow the initial postextraction remodeling to take place before initiating regenerative procedures. An early implant placement would be recommended for thin bone phenotypes. Immediate implant placement would be recommended only for thick wall phenotypes and thick gingival biotypes where minimal remodeling would be expected.

The soft tissue thickness in maxillary anterior teeth is thin in most patients, ranging from $0.5 \mathrm{~mm}$ to $1 \mathrm{~mm}$. This soft tis- 
sue thickness has not shown significant correlation to the underlying facial bone wall thickness [36]. For single extraction sites, $50 \%$ of the soft tissue change occurs within the first 2 weeks postextraction. The increase in soft tissue thickness significantly depends on the underlying bone dimensions. In thick wall phenotypes, the soft tissue dimensions do not significantly change. In these defects, the alveolus acts as a selfcontained bony defect and favors the growth of bone-forming cells from the adjacent socket walls. In thin wall phenotypes, the facial bone wall resorbs rapidly and the highly proliferative soft tissue occupies its position. There is a sevenfold increase in soft tissue occupying the crestal area of the socket defect, and this is termed as spontaneous soft tissue thickening [13]. The tissue formed is highly vascularized granulation tissue with fibroblasts migrating into it, some of which differentiate into myofibroblasts that are involved in the thickening phenomenon. At 8 weeks, there is a peak in endothelial cell density, BMP-7, and osteocalcin expression, indicating that the molecular and cellular mechanisms that regulate new bone formation also influence the soft tissue thickening. The clinical implications of this soft tissue thickening are that, after an 8 week healing period, the soft tissues are sufficiently thickened and provide increased keratinized tissue in the site that allows for primary closure favoring bone regeneration. With this thickened soft tissue, there is no requirement for additional soft tissue grafts. However, this soft tissue thickening can mask the underlying bone defect, often misleading the clinician while selecting the appropriate treatment protocol [37].

\subsubsection{Concept of Timing for Implant Placement}

Implant placement can be classified based on the timing of implant placement. According to the ITI Consensus Conferences in 2003 and 2008, it is classified as Type 1, Type 2, Type 3, and Type 4 implant placement [38].

\section{Box 18.2 Concept of Timing for Implant Placement}

Type 1: When placed immediately after tooth extraction, it is called immediate implant placement.

Type 2: When placed 4-8 weeks after tooth extraction, it is an early implant placement with only soft tissue healing

Type 3: When placed 12-16 weeks after tooth extraction, it is an early implant healing with partial bone healing

Type 4: When placed after 6 months after tooth extraction, there is complete bone healing, and this is called delayed implant placement.
The choice of timing of implant placement depends on several factors. The four options are available to the clinician, who can select the option based on the following criteria, provided that they have the required clinical expertise.

- Immediate implant placement (type I) is recommended to be performed only by experienced clinicians in sites that have ideal anatomic conditions, such as:

(i) a completely intact, thick wall phenotype (i.e., $>1 \mathrm{~mm}$ ) facial bone wall at the extraction site

(ii) thick gingival biotype,

(iii) absence of acute infection at the extraction site, and

(iv) adequate volume of bone apical and palatal of the extraction site to allow sufficient primary stability of the implant while placing it in the correct 3-dimensional position.

- Type 2 placement is recommended when the above ideal conditions are not met.

(i) In situations where there is inadequate keratinized tissue, this technique allows an additional 3-5 mm of tissue as the tissues heal spontaneously.

(ii) In sites where there is a thin facial bone, the bundle bone spontaneously resorbs and a spontaneous soft tissue thickening takes place to fill the extraction socket.

(iii) Acute and chronic infections resolve leaving the future implant site free of infections.

(iv) Bone forms in the apical portion of the socket, thus allowing primary stability from the apical bone during implant placement. At the stage of implant placement, a guided bone regeneration procedure with bone graft and membrane is most often required.

- Type 3 implant placement is recommended in cases where either primary stability cannot be achieved even after 4-8 weeks of healing postextraction or where the proper 3-dimensional position for implant placement cannot be achieved. The healing time in these cases is extended to 12-16 weeks to allow partial bone healing. This is generally ideal for multirooted teeth such as mandibular molars. In this case also, guided bone regeneration with bone graft and membrane is often required.

- Type 4 implant placement is often not a preferred treatment by the patient. However, the indications for this type of implant placement are determined by certain patientrelated factors or site-specific factors. Patient related factors include.

(i) patients with systemic conditions that require treatment to be deferred, e.g., pregnant patients,

(ii) adolescent patients who are too young to receive implants and require the treatment to be deferred, and

(iii) patients who are unable to make an early appointment due to personal reasons. 
Site-related factors include.

(a) Large Apical Lesions

(b) Impacted or ankylosed teeth that cause a lot of bone removal in the apical aspect of the site. In all these cases, it is recommended that socket grafting with a low substitution filler is used to reduce ridge alterations and ridge atrophy. The crestal bone resorption is inevitable; however, the use of socket grafting minimizes the need for ridge augmentation at a later date.

\subsubsection{Healing Modality: Concept of Submerged and NonSubmerged Healing}

When an implant is placed, the operator can choose to either submerge the implant (completely enclose it within the healing tissues) or keep it nonsubmerged (implant is visible through the healing soft tissue). (Figure 18.7 shows diagrammatic representation of submerged and nonsubmerged healing).

In the nonsubmerged/one-stage approach, the healing cap/abutment of the implant emerges through the mucosal tissues at the time of flap closure after implant placement. Nonsubmerged implants can be one-piece or two-piece implants. In one-piece implants, there is no micromovement and no microgap between the implant and the abutment. In the two-piece nonsubmerged implants, there is no need for a second surgical procedure to expose the implant for prosthetics; however, the potential of the microgap between the two components exists. This technique is generally preferred for standard implant placement procedures where there is no need to augment the site.

In the submerged/two-stage approach, the healing cap/ cover screw is completely covered with the soft tissue flap after implant placement surgery. The implants are allowed to osseointegrate in a closed environment without loading or any form of micromovement, for a period of time. The submerged protocol is used for implant placement with simultaneous bone augmentation. Following this healing period, the implant is surgically exposed to place the abutment. Both these techniques are well accepted and can be selected based on the treatment plan.

\subsection{Surgical Procedure for Conventional Implant Placement}

As mentioned before, the most important step before implant surgery is the analysis of the general patient factors and then the local edentulous site factors. Depending on whether it is an implant replacement for a single tooth, multiple teeth, or a completely edentulous ridge, the planning differs. The
Fig. 18.7 Diagrammatic representation of submerged and nonsubmerged healing

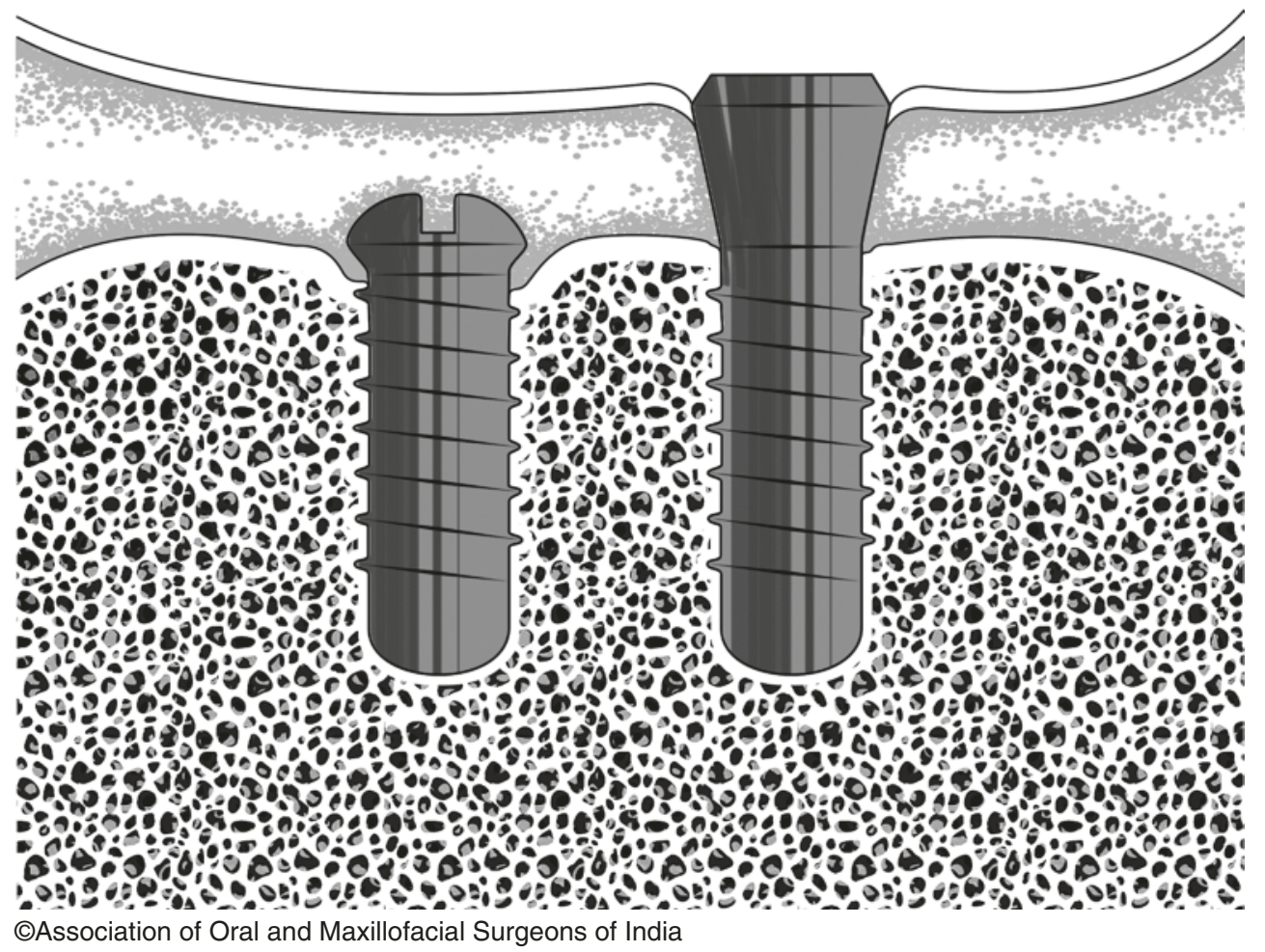


treatment protocol also differs depending on whether it is an esthetic site or not. Single tooth replacements in a nonesthetic site are simpler as compared to multiple teeth replacements in an esthetic site.

For standard implant placement:

1. Local anesthesia: the area of surgery including at least two teeth mesial and distal should be well-anesthetized.

2. Incision: a scalpel blade no 15 is used to make a horizontal paracrestal incision. This bisects the existing zone of keratinized mucosa with at least $2 \mathrm{~mm}$ on the buccal aspect of the future implant. The incision extends to one tooth mesially and distally with a papilla sparing incision. If required, a vertical release incision can be given on the distal aspect to create a triangular flap.

3. Flap elevation: A full thickness mucoperiosteal flap is elevated on the buccal and on the lingual aspect. A retraction suture can be placed in the buccal and lingual flaps if required. The crestal bone should be exposed sufficiently so as to get visible access to the implant site as well to check the palatal and buccal curvature of the ridge.

4. Flattening of the ridge: A large round rose bur is used to flatten the ridge, thus removing any bony slopes in the crestal area. This also allows removal of the narrower portions from the crest of the ridge; however, extensive removal in short ridges should be done judiciously.

5. Drilling of the osteotomy: all drilling should be done along with copious amounts of cold saline irrigation with the speed as specified by the manufacture for each particular bur/drill (generally in the range of 800-1500 rpm). It is important to keep an eye for the correct positioning and the neighboring anatomic structures during each stage of drilling.

(a) Initially, a small diamond bur is used to mark the site. The mark created corresponds to the center of the osteotomy and should be in the correct mesiodistal and buccolingual position. This bur is used to make a hole of 1-2 mm deep to create a start point for the pilot drill.

(b) The pilot drill is the first twist drill used to create the osteotomy up to the desired length. Ideally, the length of the osteotomy should be slightly more than the implant so that the implant can be placed slightly subcrestal (to compensate for future crestal bone resorption). Also, the shoulder of the future implant should be $1 \mathrm{~mm}$ apical to the cementoenamel junction of the adjacent teeth in esthetic areas to allow for a proper emergence profile. While drilling, the correct axis should be maintained. The drills should be repeatedly pumped in and out of the osteotomy to expose the bone debris to the water coolants for clearing. If multiple implants are to be placed, a guide pin is used in the first osteotomy to align the second implant before commencing the second osteotomy preparation.

(c) Subsequent drills are used in the same way as the pilot drill to enlarge the osteotomy to the desired depth.

(d) Profile drills or countersink drills are used between the sequential drills to widen the crestal part of the osteotomy to allow the next drill into the osteotomy. The countersink drill also flares the preparation to allow the placement of the cover screw over the implant without any bony interference.

(e) Bone tapping is an optional step that is required only in very dense bone. This is done at very slow speeds (20-40 rpm) without water irrigation.

6. Implant placement: implants are placed with a handpiece at slow speeds $(18-25 \mathrm{rpm})$ or by hand using a torque wrench. Implant insertion should follow the same path of insertion as that of the osteotomy. For multiple implants, guide pins serve as a direction indicator to obtain parallelism. Care is taken to insert the implant such that the microrough surface of the implant is $1-1.5 \mathrm{~mm}$ subcrestal. This prevents exposure of the rough surface of the implant to the environment during the eventual crestal bone remodeling. The implant should also be placed such that the shoulder of the implant should be at least 3-4 mm apical to the cementoenamel junction of the adjacent teeth. It is also important that primary stability is achieved at placement and the average insertion torque should be $35 \mathrm{Ncm}^{2}$; however, ISQ values are a more accurate recording as they can be measured from time to time and a comparison can be obtained unlike insertion torque, which is only a one-time measurement. Once the desired position and stability are achieved, the cover screw (for submerged healing)/healing abutment (nonsubmerged healing) should be fitted over.

7. Flap closure and suturing: the flap should be approximated so as to provide tension-free closure. If required, a periosteal release incision can be done. If a submerged healing is planned, the flap should be completely closed over the implant by primary closure. If a nonsubmerged healing is intended, then the flap is closed around the healing abutment. Although any technique of suturing is acceptable, it is preferable that for long horizontal spaces, horizontal mattress sutures along with interrupted sutures 
are placed in $4-0$ or 5-0 nonresorbable sutures. Suturing of vertical incisions and papillae is generally done with 5-0 or 6-0 nonresorbable sutures.

8. Postoperative care: Simple implant surgery in a healthy patient does not require antibiotic coverage; however, if the patient has any systemic complications or at risk of infection, it is advisable to put the patient on postoperative antibiotic coverage. Analgesics are recommended for the first few days after surgery. Patient is given routine postsurgical instructions such as use of ice packs for the first $24 \mathrm{~h}$, soft diet, no vigorous rinsing, no brushing on the surgical site, no tobacco smoking, and no vigorous exercise. Provisional replacements should not transmit direct forces to the underlying implant and should be adequately relieved from the surgical site, particularly in the early healing period (4-8 weeks). Patient is recalled on the second postsurgical day and after that 1 week postoperatively to check for healing.

9. Prosthetic phase: depending on the choice of timing to load the implant, the reopening phase can be planned. For nonsubmerged implants, often, no second surgery is required as the healing abutment is exposed. For submerged implants, the healing cap/abutment can be exposed by a small surgical procedure and a taller healing abutment can be inserted so as to allow the mucosal tissue to heal around and create an emergence profile.

(Figure 18.8 shows an example of the surgical phase of single implant placement)

\subsection{Concepts of Implant Loading}

An implant loading protocol is the time period between implant placement and the attachment of the prosthesis. The loading protocols have changed over the years, and the ITI Consensus Conferences in 2003, 2008, and 2013 had slight variations in defining them. The current definition as per the ITI Consensus Conference 2018 is as follows [39]:

- immediate loading,

- early loading,

- and conventional loading.

\section{Box 18.3 Concepts of Implant Loading}

(a) Immediate loading: Loading of dental implants earlier than 1 week after implant placement. This can be done with either a provisional prosthesis or a final prosthesis. The provisional prosthesis is used to reshape the peri-implant soft tissues for better esthetic outcomes, modify the occlusion, or evaluate a planned implant prosthesis. A final prosthesis can be directly given in cases with low esthetic risk and in areas of stable occlusion. This protocol significantly reduces the treatment time, and both soft tissue and bony healing occurs under functional loading.

(b) Early loading: Loading of dental implants between 1 week and 2 months after implant placement. In this treatment approach, functional forces are exerted on the implants during the later stages of bone healing. Soft tissues are still healing, and by two months, they are almost completely healed. Here also, the time between placement and loading is reduced.

(c) Conventional loading: Loading of dental implants more than 2 months after implant placement [40, 41]. This allows for a complete healing of bone and peri-implant soft tissue and requires a longer treatment time between implant placement and loading. This protocol is selected in cases when there are medical or risk factors, low implant stability at surgery, and extensive augmentation in the implant site and with short or narrow diameter implants.

Patient-related factors such as medical and systemic risk factors, surgical site factors (augmented site), and implant stability as assessed by insertion torque $\left(20-50 \mathrm{Ncm}^{2}\right)$ and resonance frequency analysis (>55 ISQ) are determinants for selecting the loading protocol. Implant design and characteristics also affect the loading protocol, surface modification of implants has added to faster healing rates of bone around implants, and hence, the healing period before loading has reduced [23]. Hence, selection of a correct loading protocol is case specific. 
a
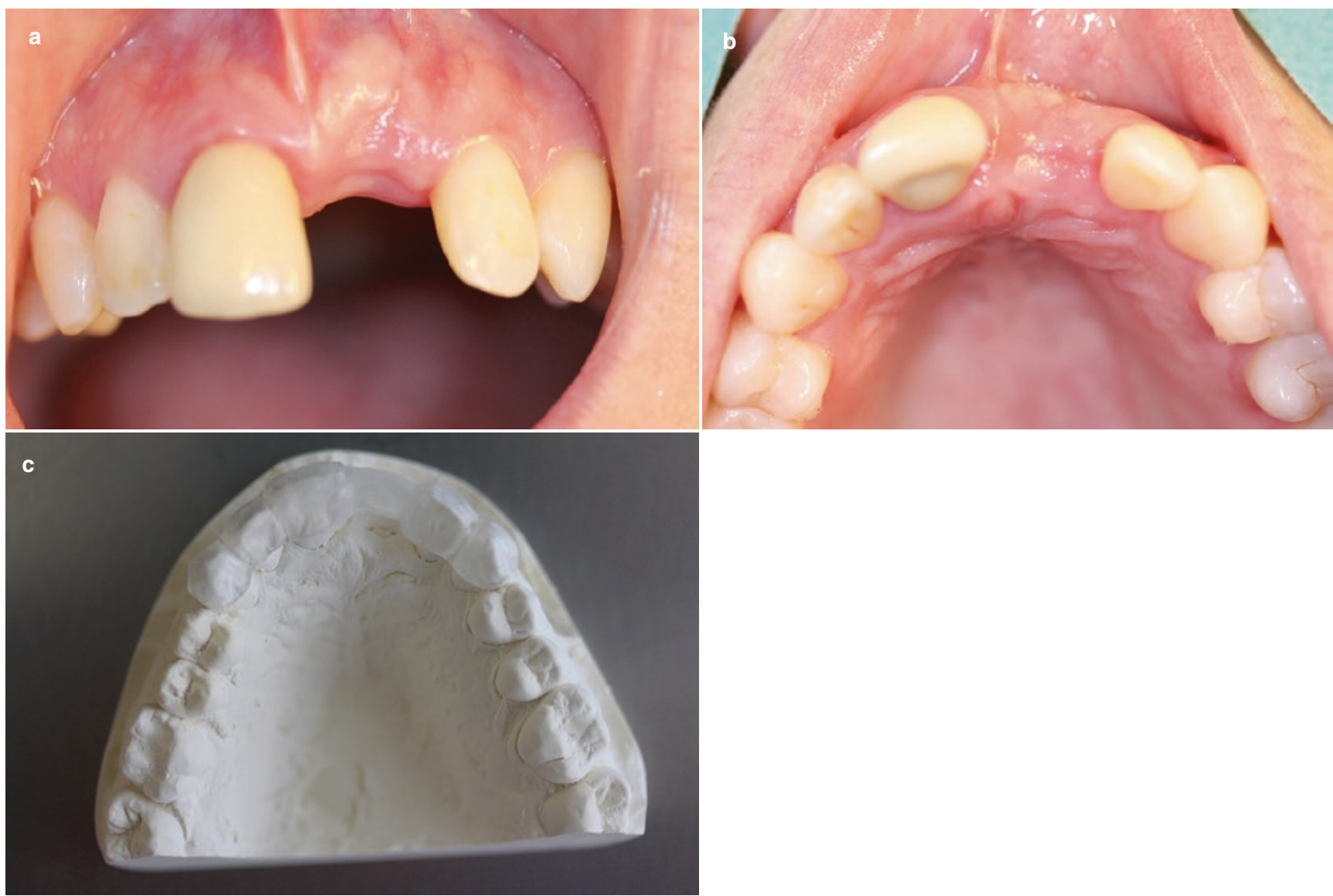

b

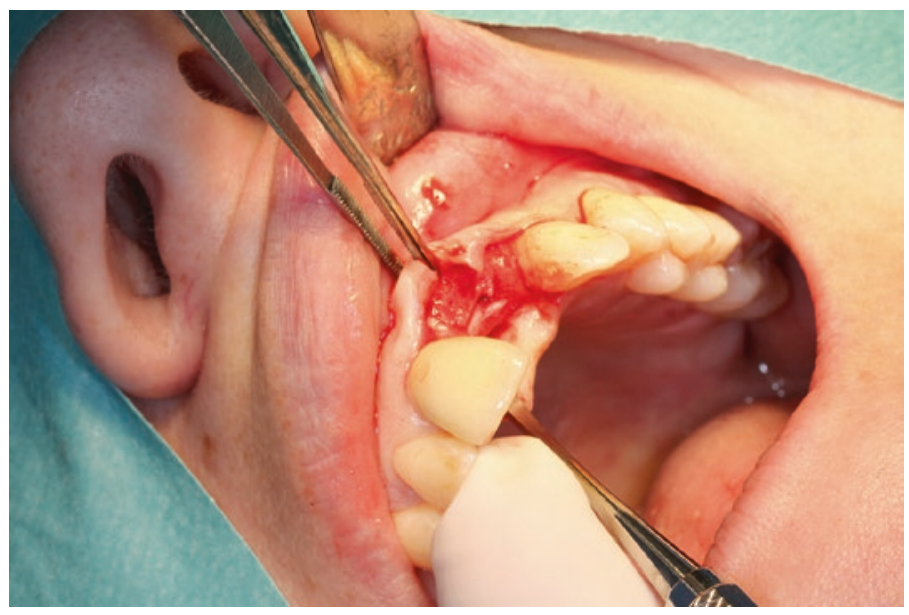

Fig. 18.8 These series of figures show steps in implant placement with restoration of a single tooth edentulous space. (aa) Preoperative facial view of edentulous space. (ab) Preoperative occlusal view of edentulous space. (ac) Preoperative master cast with surgical splint. (b) Incision and reflection of mucoperiosteal flap. (ca) Initial drilling. (cb) Checking for ideal placement of initial drill with surgical guide, which would lead to prosthodontically driven implant placement and a favor- able emergence profile. (cc) Checking for the depth of implant osteotomy using a depth gauge. (da) Subsequent drilling to accommodate the chosen dimension of the implant. (db) Subsequent drilling to accommodate the chosen dimension of the implant. (e) Implant insertion. (f) Placement of healing abutment for transmucosal/ non submerged healing. (g) Suturing and wound closure 


\section{C}
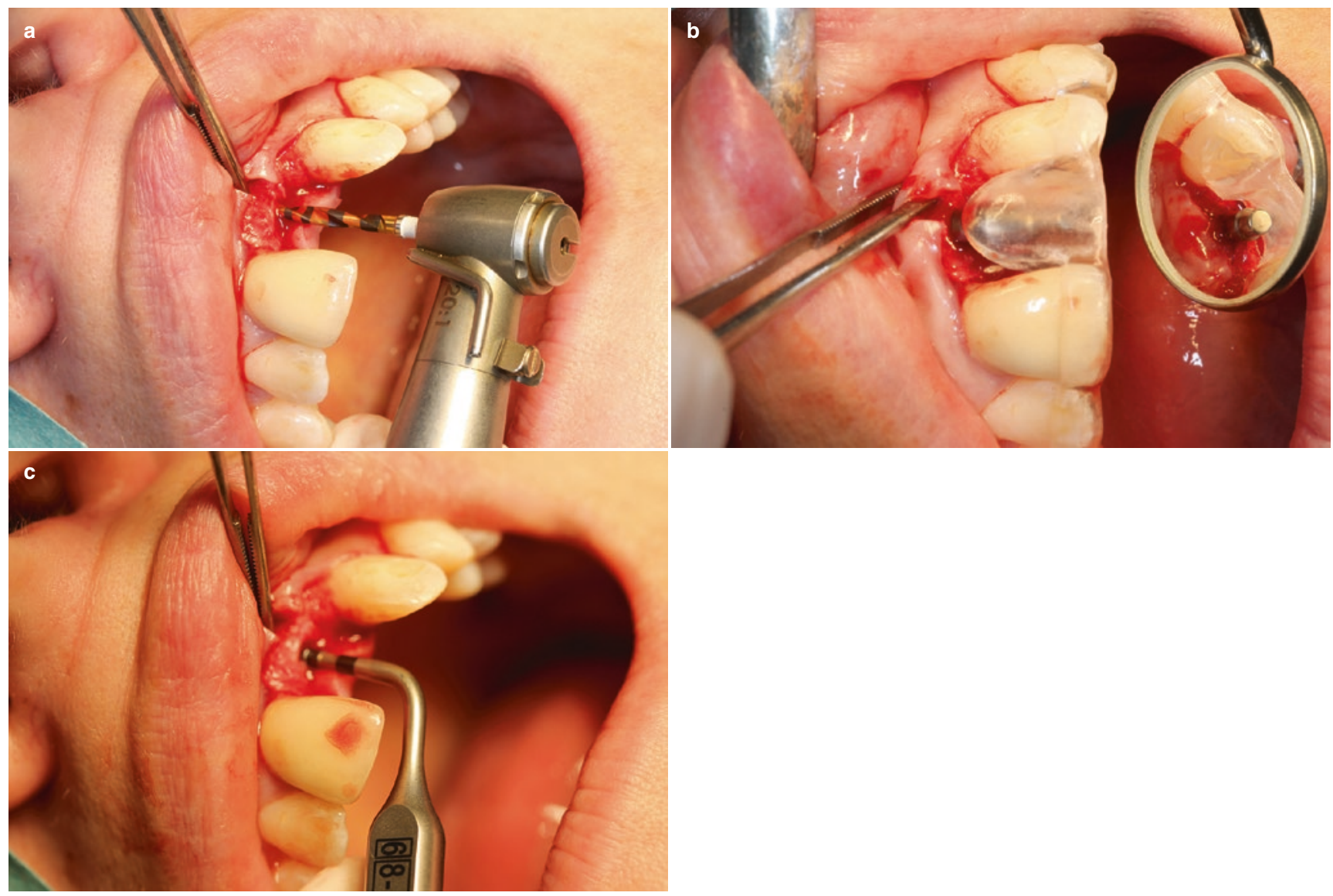

\section{d}
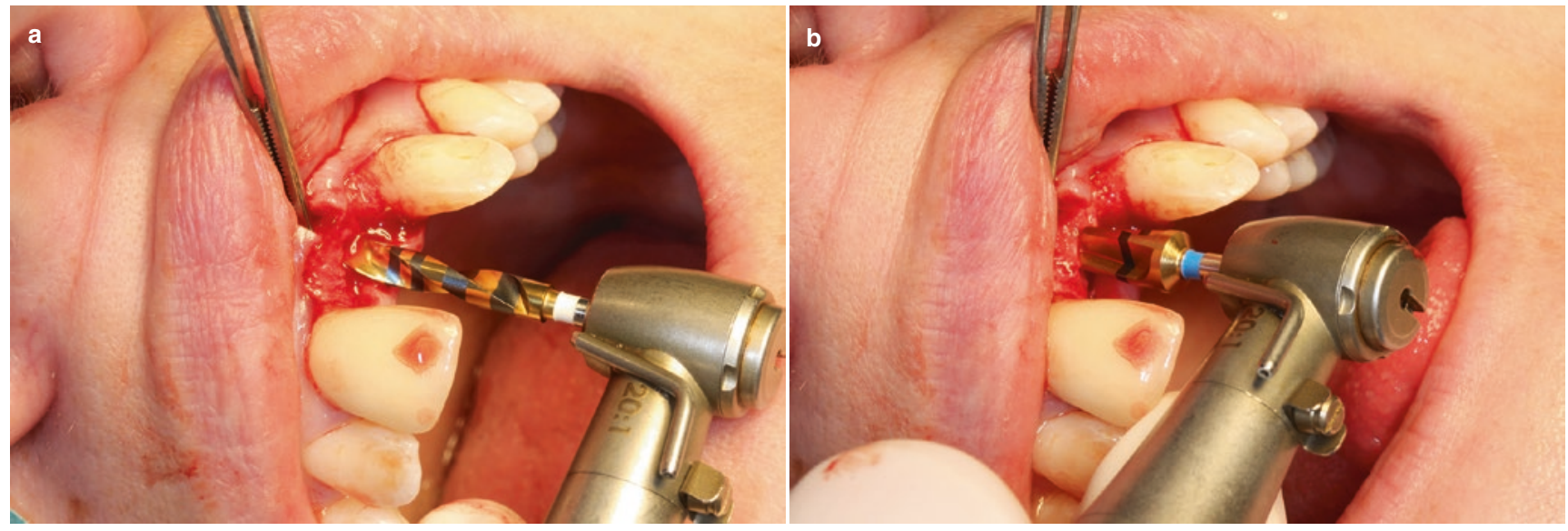

Fig. 18.8 (continued) 

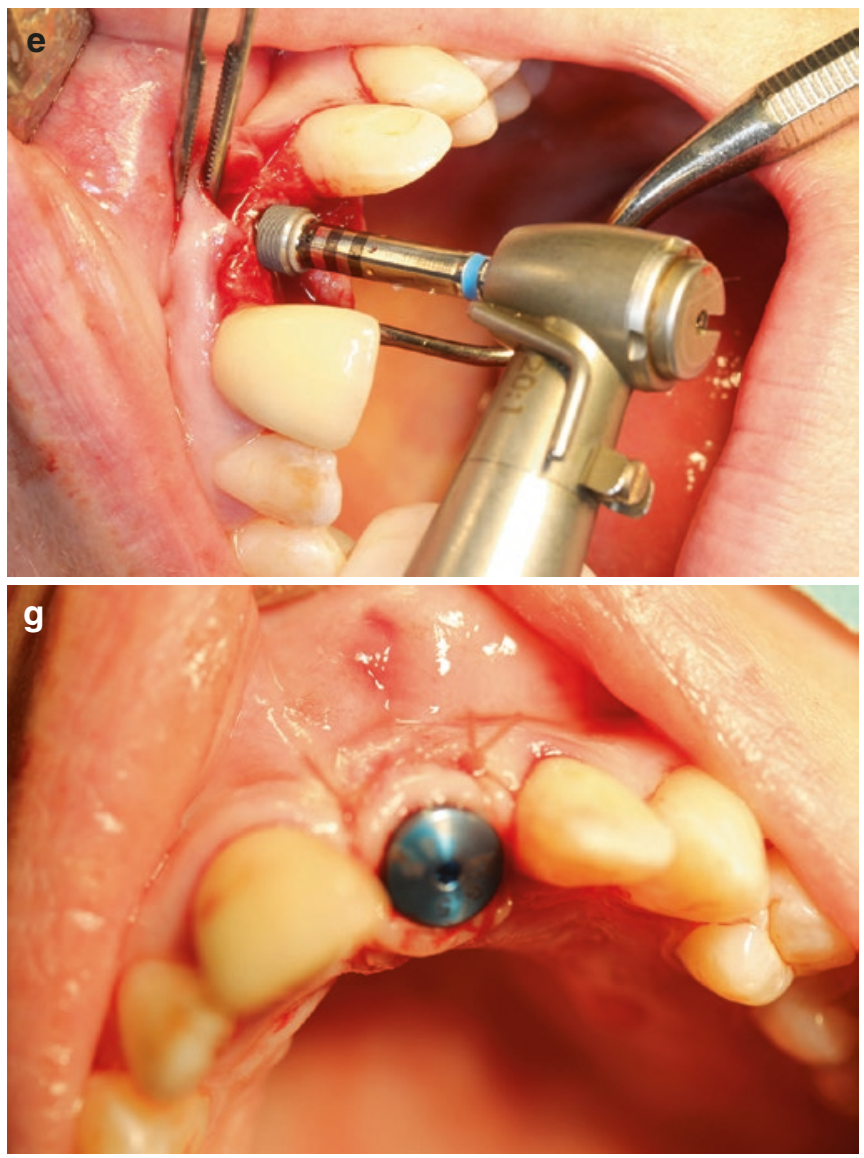

CAssociation of Oral and Maxillofacial Surgeons of India

Fig. 18.8 (continued)

\subsection{Suggested Reading}

ITI Treatment guides $1-10$.

\section{References}

1. Abraham CM. A brief historical perspective of dental implants, their surface coatings and treatment. Open Dent J. 2014;8(Suppl 1-M2):50-5.

2. Buser D, Sennerby L, De Bruyn H. Modern implant dentistry based on osseointegration: 50 years of progress, current trends and open questions. Periodontol 2000. 2017;73(1):7-21.

3. Mavrogenis AF, Dimitriou R, Parvizi J, Babis GC. Biology of implant osseointegration. J Musculoskelet Neuronal Interact. 2009;9(2):61-71.

4. BrånEmark PI. Introduction to osseointegration. In: BråNemark PI, Zarb G, Albrektsson T, editors. Tissue integrated prostheses. Osseointegration in clinical dentistry. Chicago and Tokyo: Quintessence; 1985. p. 350.

5. Stanford CM, Keller JC. The concept of osseointegration and bone matrix expression. Crit Rev Oral Biol Med. 1991;2(1):83-101.

6. Reddy VK. Osseointegration. Int Dent Med J Adv Res. 2015;1:1-7.

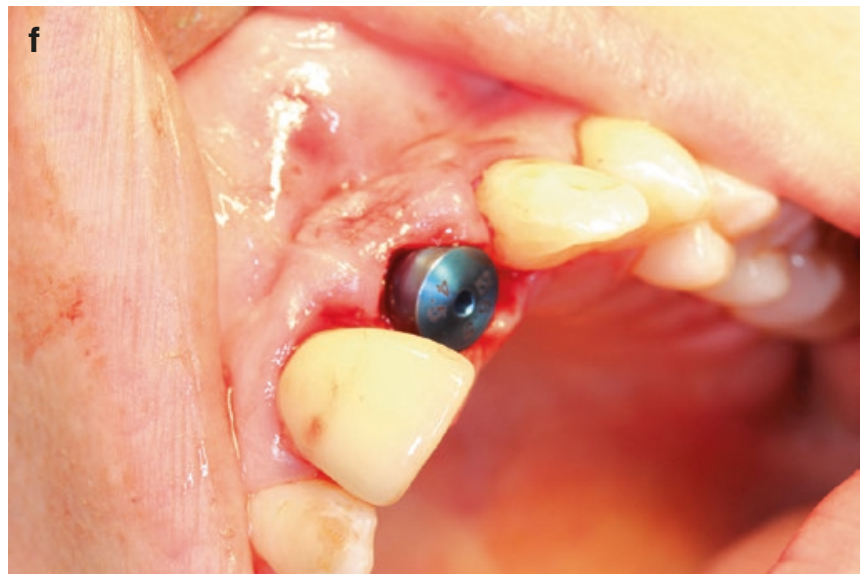

7. Albrektsson T, Albrektsson B. Osseointegration of bone implants. A review of an alternative mode of fixation. Acta Orthop Scand. 1987;58(5):567-77.

8. Osman RB, Swain MV. A critical review of dental implant materials with an emphasis on titanium versus Zirconia. Materials (19961944). 2015;8(3):932-58.

9. Vootla NR, Reddy KV. Osseointegration- key factors affecting its success-an overview. IOSR J Dent Med Sci (IOSR-JDMS). 2017;16(4):62-8. e-issn: 2279-0853, p-issn: 2279-0861

10. Ellingsen JE, Johansson CB, Wennerberg A, Holmen A. Improved retention and bone-to-implant contact with fluoride-modified titanium implants. Int J Oral Maxillofac Implants. 2004;19:659-66.

11. Novaes AB Jr, de Souza SL, de Barros RR, Pereira KK, Iezzi G, Piattelli A. Influence of implant surfaces on osseointegration. Braz Dent J. 2010;21(6):471-81.

12. Moraschini V, E dS P B. Success of dental implants in smokers and non-smokers: a systematic review and meta-analysis. Int J Oral Maxillofac Surg. 2016;45(2):205-15.

13. Chappuis V, Araujo MG, Buser D. Clinical relevance of dimensional bone and soft tissue alterations post-extraction in esthetic sites. Periodontology 2000. 2017;73:73-83.

14. Eriksson AR, Albrektsson T. Temperature threshold levels for heatinduced bone tissue injury: a vital-microscopic study in the rabbit. J Prosthet Dent. 1983 Jul;50(1):101-7. 
15. Parithimarkalaignan S, Padmanabhan TV. Osseointegration: An update. J Indian Prosthodont Soc. 2013;13(1):2-6.

16. Fiorellini J, Wada K, Stathopoulou P, Klokkevold PR. Chapter 71: periimplant anatomy, biology, and function in carranza's clinical periodontology. 12th ed. Amsterdam: Saunders, Elsevier Inc; 2015.

17. Stanford CM. Surface modifications of dental implants. Aus Dent J. 2008;53(1 Suppl):s26-33.

18. Le Guehennec L, Soueidan A, Layrolle P, Amouriq Y. Surface treatments of titanium dental implants for rapid osseointegration. Dent Mater. 2007;23:844-54.

19. Albrektsson T, Wennerberg A. Oral implant surfaces: part 1--review focusing on topographic and chemical properties of different surfaces and in vivo responses to them. Int J Prosthodont. 2004 Sep-Oct;17(5):536-43.

20. Buser D, Schenk RK, Steinemann S, Fiorellini JP, Fox CH, Stich $\mathrm{H}$. Influence of surface characteris- tics on bone integration of titanium implants. A histo- morphometric study in miniature. J Biomed Mater Res. 1991;25:889-902.

21. Wennerberg A. The role of surface roughness for implant incorporation in Bone. Cells Mater. 1999;9(1):1-19.

22. Lang NP, Salvi GE, Huynh-Ba G, Ivanovski S, Donos N, Bosshardt DD. Early osseointegration to hydrophilic and hydrophobic implant surfaces in humans. Clin Oral Implants Res. 2011 Apr;22(4):349-56.

23. Buser D, Broggini N, Wieland M, Schenk RK, Denzer AJ, Cochran DL, Hoffmann B, Lussi A, Steinemann SG. Enhanced bone apposition to a chemically modified SLA titanium sur- face. J Dent Res. 2004;83(7):529-33.

24. Al-Johany SS, Al Amri MD, Alsaeed S, Alalola B. Dental implant length and diameter: a proposed classification scheme. J Prosthodont. 2017 Apr;26(3):252-60.

25. Buser D, Martin W, Belser UC. Optimizing esthetics for implant restorations in the anterior maxilla: anatomic and surgical considerations. Int J Oral Maxillofac Im- plants. 2004;19(suppl):43-61.

26. Grunder U, Gracis S, Capelli M. Influence of the 3-D bone-toimplant relationship on esthetics. Int $\mathrm{J}$ Periodon Restor Dent. 2005;25:113-9.

27. Klokkevold PR, Cochran DL. Clinical evaluation of the implant patient. Chapter 72, carranzas clincical periodontology. 12th ed. Amsterdam: Elsevier. p. 693-705.

28. Dawson A, Chen S, Buser D, Cordaro L, Martin W, Belser U. In: Dawson A, Chen S, editors. The SAC classification in implant dentistry. Chicago, IL: Quintessence Publishing; 2009.

29. Cardaropoli G, Araujo M, Lindhe J. Dynamics of bone tissue formation in tooth extraction sites. An experimental study in dogs. J Clin Periodontol. 2003;30:809-18.
30. Araujo MG, Lindhe J. Dimensional ridge alterations following tooth extraction: an experimental study in the dog. J Clin Periodontol. 2005;32:212-8.

31. Schropp L, Wenzel A, Kostopoulos L, Karring T. Bone healing and soft tissue contour changes following single-tooth extraction: a clinical and radiographic 12-month prospective study. Int J Periodontics Restorative Dent. 2003;23:313-23.

32. Ten Heggeler JM, Slot DE, Van der Weijden GA. Effect of socket preservation therapies following tooth extraction in non-molar regions in humans: a systematic review. Clin Oral Implants Res. 2011;22:779-88.

33. Trombelli L, Farina R, Marzola A, Bozzi L, Liljenberg B, Lindhe $\mathrm{J}$. Modeling and remodeling of human extraction sockets. J Clin Periodontol. 2008 Jul;35(7):630-9.

34. Chappuis V, Engel O, Reyes M, Shahim K, Nolte LP, Buser D. Ridge alterations post-extraction in the esthetic zone: a 3D analysis with CBCT. J Dent Res. 2013;92:195S-201S.

35. Chen ST, Buser D. Clinical and esthetic outcomes of implants placed in postextraction sites. Int $\mathbf{J}$ Oral Maxillofac Implants. 2009;24(Suppl):186-217. Review

36. Chappuis V, Engel O, Shahim K, Reyes M, Katsaros C, Buser D. Soft tissue alterations in esthetic postextraction sites: a 3-dimensional analysis. J Dent Res. 2015 Sep;94(9 Suppl):187S-93S.

37. Morton D, Chen ST, Martin WC, Levine RA, Buser D. Consensus statements and recommended clinical procedures regarding optimizing esthetic outcomes in implant dentistry. Int J Oral Maxillofac Implants. 2014;29(Suppl):216-20.

38. Buser D, Chappuis V, Belser U, Chen S. Implant placement post extraction in esthetic single tooth sites: when immediate, when early, when late? Periodontology 2000. 2017;73:84-102.

39. Gallucci GO, Hamilton A, Zhou W, Buser D, Chen S. Implant placement and loading protocols in partially edentulous patients: a systematic review. Clin Oral Implants Res. 2018;29(Suppl. 16): $106-34$

40. Gallucci GO, Benic GI, Eckert SE, Papaspyridakos P, Schimmel M, Schrott A, Weber HP. Consensus statements and clinical recommendations for implant loading protocols. Int J Oral Maxillofac Implants. 2014;29(Suppl):287-90.

41. Weber HP, Morton D, Gallucci GO, Roccuzzo M, Cordaro L, Grutter L. Consensus statements and recommended clinical procedures regarding loading protocols. Int J Oral Maxillofac Implants. 2009;24(Suppl):180-3.

Open Access This chapter is licensed under the terms of the Creative Commons Attribution 4.0 International License (http://creativecommons. org/licenses/by/4.0/), which permits use, sharing, adaptation, distribution and reproduction in any medium or format, as long as you give appropriate credit to the original author(s) and the source, provide a link to the Creative Commons license and indicate if changes were made.

The images or other third party material in this chapter are included in the chapter's Creative Commons license, unless indicated otherwise in a credit line to the material. If material is not included in the chapter's Creative Commons license and your intended use is not permitted by statutory regulation or exceeds the permitted use, you will need to obtain permission directly from the copyright holder. 